\author{
Federal Reserve Bank of New York \\ Staff Reports
}

\title{
Momentum and the Term Structure of Interest Rates
}

\author{
J. Benson Durham
}

Staff Report No. 657

December 2013

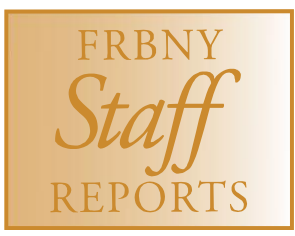

This paper presents preliminary findings and is being distributed to economists and other interested readers solely to stimulate discussion and elicit comments. The views expressed in this paper are those of the author and are not necessarily reflective of views at the Federal Reserve Bank of New York or the Federal Reserve System. Any errors or omissions are the responsibility of the author. 


\author{
Momentum and the Term Structure of Interest Rates \\ J. Benson Durham \\ Federal Reserve Bank of New York Staff Reports, no. 657 \\ December 2013 \\ JEL classification: G10, G12, G15
}

\begin{abstract}
A vast literature reports excess returns to momentum strategies across many financial asset classes. However, no study examines trading rules based on price history along individual government-bond term structures - that is, with respect to duration buckets across the curve - as opposed to across sovereign markets or individual term structures as a whole over time. Under duration-neutral and long-only constraints as well as low trading costs, this paper reports excess annualized returns of up to 120 basis points and information ratios as high as 0.79 using U.S. Treasury total return data from December 1996 through July 2013. Given a corresponding longshort strategy with no absolute duration risk, excess returns and information ratios are up to 207 basis points and 1.01, respectively. Unlike momentum strategies in some other asset classes, the excess return distributions are positively skewed, and momentum loads, if in any way, favorably on broad risk factors. Returns correlate to a degree with portfolios based on instantaneous forward term premium estimates, in turn derived from a set of Gaussian arbitrage-free affine term structure models. However, substantial variance remains unexplained, the betas are less than one, and the alphas are meaningfully positive. A caveat is that underlying behavioral explanations for momentum are lacking in the context of the U.S. Treasury market.
\end{abstract}

Key words: momentum anomaly, interest rates

Durham: Federal Reserve Bank of New York (e-mail: jbenson.durham@ny.frb.org).Without implication, the author thanks Tobias Adrian, Nina Boyarchenko, Richard Crump, Fernando Duarte, Ernst Schaumburg, Andreas Schrimpf, and seminar participants at the Bank for International Settlements and the Federal

Reserve Bank of New York for helpful comments. The views expressed in this paper are those of the author and do not necessarily reflect the position of the Federal Reserve Bank of New York or the Federal Reserve System. 


\section{Introduction}

A large and growing literature documents a sizeable momentum anomaly across several financial asset classes. Portfolios comprised of assets with the most positive (negative) prior excess returns subsequently tend to have superior (inferior) risk-adjusted results. ${ }^{1}$ Studies document momentum profits with respect to individual shares (Jegadeesh and Titman, 1993; Rouwenhorst, 1999), aggregate equity market indexes (Asness et al., 1997; Durham, 2001), currencies and commodities (e.g., Menkhoff et al., 2012; Gorton et al., 2012; Ilmanen, 2011; Asness et al., 2013; Moskowtiz, 2012), and speculative- rather than investment-grade corporate bonds (Jostova et al., 2013). Empirical tests usually comprise sorting portfolios based on past returns that are long or over-weight past winners and short or under-weight past losers, calculating corresponding returns, and evaluating risk exposure with imperfect proxies. Researchers ubiquitously and dutifully note that abnormal momentum returns might comprise statistical aberrations that ultimately owe to data mining, compensation for risk undetected by standard asset-pricing models, possible limits to arbitrage (Shleifer and Vishny, 1997), or true opportunities to exploit market inefficiency. Under the strong assumptions of anomalous yet statistically robust results as well as trading conditions that do not unduly inhibit arbitragers, two strands of behavioral explanations figure prominently in the literature. First, momentum patterns might reflect cognitive biases among a substantial enough subset of (representative) investors to generate such patterns, such as over-confidence, self-attribution bias (e.g., Daniel et al., 1998), or the disposition effect (e.g., Frazzini, 2006). ${ }^{2}$ Second, abnormal returns might trace to dynamics that produce market inefficiencies or (predictable) speculative

\footnotetext{
${ }^{1}$ Substantial research also documents a contrarian effect, following DeBondt and Thaler (1985), and some studies purport to reconcile such market under- and over-reaction (e.g., Hong and Stein, 1999; Barberis et al., 1998).

${ }^{2}$ See Ilmanen (2011) for a more comprehensive overview of behavioral explanations.
} 
dynamics among heterogeneous investors limited by bounded rationality (e.g., Hong and Stein, 1999; Cutler et al., 1990, 1991).

Despite strong incentives, to date analyses of cross-sectional momentum along government bond term structures-i.e., momentum patterns with respect to duration buckets across the curve - rather than across different markets or individual curves as a whole over time, has eluded this rich literature. This study reports sizeable excess returns, notably under the duration-neutral constraint and without short sales, of up to 120 basis points in annual terms, with information ratios up to around 0.79 , given all necessary available U.S. Treasury data from December 1996 through July 2013. Relaxing the short selling constraint to produce portfolios with no absolute duration risk produces returns up to 207 basis points, with information ratios up to 1.01. Unlike momentum strategies in other asset classes, as well as carry trades for that matter, the return distributions for long-only and long-short strategies are skewed to the upside, and term structure momentum does not load on common risk factors but seems to, if anything, correlate favorably as a hedge against risky assets and some liquidity proxies. Data on Japan and Canada, but not necessarily the U.K., corroborate the general results for the U.S., though the evidence is somewhat uneven and sensitive to look-back windows.

The analyses do not seem to imply that U.S. returns are conditioned on any identifiable ex ante factors, perhaps of particular interest to practitioners. There is some limited evidence that term structure momentum is Treasury market state-dependent, at least contemporaneously, given a positive correlation between overall market and momentum returns, but the result is much less pronounced compared to evidence on shares (Cooper et al., 2004), and such contemporaneous conditionality does not connote risk exposure per se. Also, there does not appear to be any positive relation between the underlying magnitude of the momentum signal 
and subsequent returns. In addition, under the suspicion that momentum strategies might embed compensation consistent with forward term premium estimates, ${ }^{3}$ momentum returns do correlate to a degree with portfolio returns based on Gaussian arbitrage-free affine term structure models (GATSMs). As a caveat, similar to shortcomings in the CAPM with respect to comprehensive risk measurement, GATSMs may not, perhaps particularly in the current environment, capture duration risk—i.e., term premiums—satisfactorily (Bauer and Rudebusch, 2012; Durham, 2013). Nonetheless, the following includes substantial sensitivity analyses with respect to the sample selection underlying GATSM parameter estimation, substantial variance remains unexplained, the betas are less than one, and the alphas are positive. However, to date common behavioral explanations for momentum returns relevant for, say, shares, seem less relevant in the specific context of the U.S. Treasury market.

The remainder of this study is organized as follows. Section 2 reviews the small literature on bond market momentum, and Section 3 outlines novel duration-neutral long-only strategies that exploit momentum in broad curve positions. Section 4 outlines the distribution of unconditional positive abnormal returns for the U.S., and Section 5 similarly details the results from relaxing the short sales constraint. Section 6 describes the results for Japan, Canada, and the U.K., and Section 7 summaries momentum return exposures to alternative dimensions of common risks. Section 8 considers whether returns are conditioned on ex ante state-dependent factors, and Section 9 examines the relation between the apparent anomaly and the output of standard GATSMs, namely term premium estimates. Section 9 concludes.

\section{The Small Literature on Momentum and Government Bonds}

\footnotetext{
${ }^{3}$ The term premium is the additional return investors require to hold longer- as opposed to shorter-duration instruments - the difference between the yield on a bond and the estimated average expected instantaneous short rate over its maturity.
} 
Asness et al. (2013) examine the dynamics of value and momentum investment strategies across several asset classes, including some analyses of simple trading rule across government bond markets. ${ }^{4}$ Their analysis closely parallels studies of country stock returns (Asness et al., 1997), and they report results on the cross-section of "country bond" returns-i.e., trading rules based on isolating winners and losers among six to 10 government bond markets (depending on data availability). In addition, Moskowitz et al. (2012) document significant "time-series" momentum, as opposed to the cross-sectional variety, among several asset classes, including 13 bond futures contracts. In short, returns on individual bond markets appear to persist. Note that these two strategies expose the investor to country and/or duration risk.

Also, and as Ilmanen (2011) suggests in general, the magnitude of the gains to momentum across government bond markets reported in Asness et al. (2013) is not particularly compelling, and indeed cumulative abnormal returns to momentum are not positive until the mid-2000s, starting from the late 1970s. In addition, returns generated from momentum appear to be much lower than from value (i.e., based on an estimate of real yields as the underlying metric), as the reported Sharpe ratios are 0.08 and 0.40 , respectively. Moreover, in contrast to the other asset classes they consider (e.g., individual stocks in the U.S., U.K., Europe, and Japan; equity country selection; currency selection; and commodity selection), the value strategy for government bonds, measured by a proxy for real yields, has greater returns than the combination of value and momentum, as the latter represents a drag on the former over the sample. As such, the benefits from diversification across momentum and value strategies are less obvious given the cross section of bond markets.

\footnotetext{
${ }^{4}$ Jostova et al. (2013) find that non-investment-grade issuers generate momentum patterns among corporate bonds, independent of equity return momentum.
} 
Besides modest abnormal (cross-sectional) momentum returns, there are perhaps some measurement issues to reconsider. For example, whereas the results from Moskowitz et al. (2012) clearly do, it is unclear whether the cross-sectional country-bond portfolios (Asness et al., 2013) expose the investor to overall duration risk. Given that average duration differs across markets, and undoubtedly global factors influence local market interest rates, abnormal returns to "past winners" should transcend general (global) duration effects. And, the analysis of the alpha and beta of these published strategies uses a proxy for the global CAPM, which is arguably too crude a benchmark to capture systemic risk across sovereign bond markets, and as noted below, perhaps GATSMs would be a preferable metric. Nonetheless, Asness et al. (2013) and Moskowtiz et al. (2012) usefully raise the prospect of finding momentum profits using term structures.

\section{A Duration-Neutral Trading Rule along (not across) Yield Curves}

Rather than across government bond markets, in effect country bond selection, or timeseries momentum for individual curves, the following outlines simple trading rules along the term structure that do not expose the investor to parallel shifts in the yield curve. Despite somewhat limited cross-sectional breadth, such strategies can be constructed using total return as well as required duration and market value data on the six sub-indexes of the nominal U.S. Treasury market based on the following buckets-1- to 3-, 3- to 5-, 5- to 7-, 7- to 10-, 10- to 20-, and 20- to 30-year maturities. The measure of momentum follows the standard approach in the literature, i.e., average total returns for each duration bucket from between two through, alternatively, five to 13 months prior. ${ }^{5}$

\footnotetext{
${ }^{5}$ Novy-Marx (2012) addresses the window length in the context of individual shares and reports more predictive information between six and 12 months rather than more recent periods.
} 
However, the signal for evaluation and ultimate portfolio formation is somewhat distinct compared to, say, Asness et al. (2013) by following a continuous construction rather than discrete rankings. For each month in the sample, the momentum portfolio is the allocation across the six buckets that has the greatest past return, under two simple linear-programming constraints. First, the portfolio weights are bound between zero and one and therefore preclude short sales. As such, the strategy is applicable for long-only investors. Second, the portfolio weights produce an allocation with the same contemporaneous weighted-average duration as the benchmark. Thus, any anomalous excess return over the index by construction cannot represent compensation for aggregate duration risk, or perhaps more precisely, exposure to parallel shifts in the term structure.

More formally, the simple linear programming objective function is to select the optimal $6 \times 1$ vector of weights for time-series observation $t, w_{t}^{o p t}$, that maximizes

$$
\left(w_{t}^{o p t}\right)^{T} \bar{R}_{(t-2: t-n), t}
$$

where $\bar{R}_{(t-2: t-n), t}$ is the $6 \times 1$ vector of average returns from prior time periods $t-2$ through $t-n$ (the $n$-month length of the look-back window). The constraints are that each element of $w_{t}^{\text {opt }}$ is between zero and one and that

$$
\left(w_{t}^{\text {opt }}\right)^{T} D_{t}=d_{t}^{\text {index }}
$$

where $D$ is the $6 \times 1$ vector of duration mid-points for each maturity bucket, and $d^{\text {index }}$ is the overall U.S. Treasury index duration at time $t$. Again, this signal is distinct from common rankings found in the literature, and its continuous rather than ordinal construction, along with the simple constraints, arguably more effectively captures the signal by not losing information with discrete ordering. 


\section{Unconditional Duration-Neutral Long-Only Abnormal U.S. Returns}

Turning to unconditional results, Barclays Capital data on index values, durations, and market capitalizations are available on each duration bucket beginning in December $1996{ }^{6}$ Therefore, for the 11-month momentum window between two and 12 months prior, the data comprise 187 monthly observations, from January 1998 (using returns from January 1997 through November 1997) until July 2013.

The unconditional returns suggest a sizeable anomaly, and again by construction without required short sales or exposure to duration risk in terms of parallel shifts in the yield curve. As noted in Exhibit 1, the average (annual) excess return over the benchmark for the period is about 96 basis points. The ex post tracking error-the standard deviation of those excess returns in annual terms - is 150 basis points, for an information ratio of 0.64 with a t statistic of about 8.77. By visual inspection, the time-series appears volatile but nonetheless fairly stationary throughout the sample, and unlike value strategies with some asset classes, the recent global financial crisis does not appear to be particularly problematic for the trading rule. Also, given that profitability does not seem to vary significantly over time, the so-called limits to arbitrage are perhaps less pronounced, as opposed to some currency strategies (Menkhoff et al., 2012). In addition, dissimilar to momentum returns in other asset classes, as well as carry trades, Exhibit 2 suggests that the returns are positively rather than negatively skewed. The standard skew statistic is safely greater than zero, and octile skew, which assesses symmetry toward the center of the distribution as opposed to the tails, is positive as well. Excess returns are positive for almost 60 percent of the sample, which more crudely also suggests upside skew.

\footnotetext{
${ }^{6}$ The start date of the sample notably follows the initial publication of the momentum anomaly in shares by several years.
} 
Exhibit 3 shows that the findings are insensitive to the momentum window, alternative values for $n$. Average annualized returns given 5- to 13-month (6- to 12-month) lag end points, Columns 1 through 9 (2 through 8), range from about 54 to 120 (95 to 120) basis points in annual terms, with the 9-month lag the "optimal" length, and the skew statistics for each alternative are positive. With respect to implementation, the average momentum allocations over the sample are overweight intermediate maturities, the 5- to 7- and 7- to 10-year maturity buckets, for each value of $n$. However as Exhibit 4 illustrates, allocations over the last 18 months of the sample have steadily resembled barbell strategies.

In contrast to currency momentum, which requires allocations to less liquid markets with high idiosyncratic volatility and elevated country risk (Menkhoff et al., 2012), trading costs appear to be very modest. Mean turnover across look-back windows for the duration-neutral strategy ranges from about 0.34 percent to 0.14 percent per month, as noted in Exhibit 3, with longer windows requiring less frequent rebalancing. Any calculation of transaction costs necessitates difficult choices, but consider the average (maximum) bid-ask spread, expressed in yield terms, across the nominal U.S. Treasury term structure-i.e., every CUSIP outstanding with between one and 30 years to maturity as well as on- and off-the-run status-at the time of writing, equal to about 0.62 (2.8) basis points. ${ }^{7}$ Given that monthly turnover for the most profitable strategy over the sample is about 0.21 , the full average (maximum) bid-ask spread then corresponds to trading costs of about 1.5 (7.1) basis points per year, which compares favorably to the annualized mean excess return of about 120 basis points and implies a very modest drag on profits.

\footnotetext{
${ }^{7}$ Note that the average bid-ask spread across all outstanding securities is potentially substantially greater than for the most liquid on-the-run securities.
} 
Another way to consider transaction costs is to calculate the average bid-ask spread over the sample required to reduce the statistical significance of the information ratios below, say, the standard 95 percent confidence interval. Exhibit 3 also lists these calculations - the "Bid-Ask Significance Threshold (bps)"-across alternative windows using a t statistic of 1.96, the assumption that excess returns are normally distributed, the number of monthly observations, and the tracking error and the turnover of the corresponding strategy. The implied required average bid-ask spreads range from about 9 to 56 basis points, which are notably greater than reported ranges of actual values in previous studies of Treasury market liquidity (e.g., Flemming, 2003) and contemporary quotes, as again the maximum spread for a single CUSIP today is about 2.8 basis points. ${ }^{8}$ Therefore, the transaction costs in the Treasury market required to make excess returns from the duration-neutral strategy statistically insignificant from zero seem extraordinarily high compared to reasonable expectations for market trading conditions.

\section{Unconditional Long-short, Treasury-Market-Neutral Abnormal U.S. Returns}

Relaxing the short sales constraints produces even greater abnormal returns. Exhibit 5 shows the time-series of results from a simple strategy that is simultaneously long the durationneutral portfolio described previously but short the allocation with the lowest momentum or prior return-i.e., following the minimization rather the maximization of (1). The permissible range of portfolio weights across the six duration buckets is bound between -1 and 1 , but as opposed to (2), the duration constraint follows $\left(w_{t}^{o p t}\right)^{T} D_{t}=0$. Therefore, with zero absolute duration exposure, this design is in effect "Treasury-market-neutral" and resembles long-short equity

\footnotetext{
${ }^{8}$ The threshold bid-ask spread, $b$, expressed in monthly terms, that produces a statistically insignificant information ratio for the trading strategy corresponds to the following expression,

$$
\frac{r_{m o m, n}-b t}{\sigma_{t e}} \sqrt{N} \leq 1.96
$$

where $r_{\text {mom, },}$ is the mean excess return on the momentum portfolio over the sample, $t$ is the average turnover, $N$ is the number of monthly observations, and $\sigma_{t e}$ is the tracking error.
} 
portfolios that short shares with the worst prior returns to finance long positions in stocks with the greatest momentum.

Turning to the results, the average excess return for the 12-month window increases to about 207 basis points, with an information ratio of 1.01. In addition, as indicated in Exhibit 6, the distribution of returns is similarly skewed to the upside, like the long-only strategy, using both the standard measure and octile skew. Also, the results are largely insensitive to alternative look-back windows. Exhibit 7 shows that excess returns and information ratios range from about 91 to 207 basis points and from 0.42 to 1.01 , respectively, and again the 5-month lag produces by far the least promising result. Turnover costs are quite comparable to the long-only strategy, especially for longer windows, and suggest a very modest drag on profits.

\section{Out-of-Sample Results: Japan, Canada, and the U.K.}

Some researchers might interpret the results in the previous section broadly as another out-of-sample test of the broader momentum anomaly. Indeed, if abnormal returns reflect cognitive failings among either the representative investor and/or the interactions among heterogeneous market participants, then momentum patterns should be fairly ubiquitous across asset classes, with some allowances perhaps for liquidity or other considerations regarding market microstructure. However, another question with respect to the term structure, obviously germane to fixed income portfolio managers, is the extent to which this finding is consistent across countries, i.e., within other nominal government bond markets. Besides robustness, a key motivation is the potential breadth of the strategy.

Before describing some results, data availability unfortunately limit the scope for this analysis considerably. Sufficient information on market capitalization index weights for the six duration buckets, in addition to total returns, are only available for the non-U.S. cases of Japan, 
Canada, and the U.K. for a reasonably lengthy sample using the Citigroup World Government Bond Index data. Also, and more important, another substantive consideration is the extent to which, or rather just how, global bond returns and relative returns to curve positions are correlated across global sovereign markets. For example, some studies suggest that U.S. Treasury yields on balance Granger-cause other government bond yields or swap rates (e.g., Fornari, 2004; Laopodis, 2010), or that macroeconomic data releases in the U.S. affect non-U.S. government yields, whereas non-U.S. data releases on net have limited influence on U.S. yields. In short, to the extent that U.S. rates are exogenous, non-U.S. data are perhaps superfluous as a confirmation of momentum patterns, with limited (uncorrelated) extension of strategy breadth.

Nevertheless, some evidence from other countries suggests similar momentum patterns in local currency terms (i.e., unhedged), although the results are uneven and less compelling compared to the U.S. As noted in Exhibit 8, which considers the long-only strategy, and perhaps consistent with some correlation across markets, the relative weights for Japan suggest that the average momentum portfolio is concentrated in intermediate maturities, ${ }^{9}$ as in the U.S. Also, information ratios are in general positive and peak at around 0.44 with a t statistic of about 5.74. However, longer look-back windows, notably beyond eight months, produce less compelling abnormal returns (if any in the case of the 9-month lag), which in addition do not seem to have a benevolent positive skew, unlike the U.S. case. The results for Canada, listed in Exhibit 9, on balance similarly seem consistent with the general momentum pattern, and the average allocation is also bulleted. However, similar to the Japanese case, abnormal returns appear sensitive to lag length, although in this case the longer windows produce greater information ratios, with a maximum of about 0.48 with a t statistic of about 6.13 (and with more modest positive skew

\footnotetext{
${ }^{9}$ Even though the portfolios are duration-neutral, the case of Japan might be particularly instructive given a less pronounced structural decline in the level of interest rates compared to the U.S. during the sample period.
} 
compared to the U.S. results) using the 2- through 11- and 12-month intervals. Finally, turning to Exhibit 10, data for the U.K. largely indicate no anomaly. Although seven of the nine windows produce positive information ratios, none appear to be statistically significant with at least 95 percent confidence.

\section{Does Term Structure Momentum Increase Exposure to Common Risk Factors?}

At least for the U.S., the unconditional results arguably appear just as promising for active investors, and as problematic for the rational expectations hypothesis, as previously reported price history anomalies in other financial markets. The required strategy generates large information ratios and is neutral duration as well as long-only and produces consistent and positively skewed excess returns, without excessive required turnover and transaction costs. Even so of course, an apparent pattern might not be anomalous if returns simply reflect "risk" compensation, which in this particular market might include any priced factor besides exposure to parallel curve shifts.

As a strong caution, priced factors need not necessarily be observable, but the standard approach to assess broad risk exposure is to regress returns from the strategy on a number of suspected common factors, following

$$
r_{M O M(t, n)}=\alpha+\beta^{T} X_{t}+\varepsilon_{t}
$$

where $r_{M O M(t, n)}$ is the contemporaneous return on the momentum portfolio for period $t$ with lag

length $n, \beta$ is the vector of coefficients on state vector $X$ of possible risk measures, $\alpha$ is the intercept, and $\varepsilon$ is a normally distributed (OLS) error term.

Variables in $X$ for this application span three alternative dimensions of risk and include, first, returns and/or spreads on risky assets as well as macroeconomic indicators (S\&P 500 returns, BBB spreads, oil and gold price changes, the surprise component of non-farm payroll 
data releases, etc.); second, liquidity premium proxies (3-month TED spreads, 10-year on-therun nominal Treasury premiums, 1-month A2P2 commercial paper spreads, etc.), and third, option-implied volatility measures (the VIX and the MOVE index). ${ }^{10}$ Simply put, if the loadings on momentum returns are statistically significant and economically meaningful, then the results are less anomalous and more consistent with compensation commensurate with reasonably efficient markets.

A problem for such an assessment is that the literature produces no consensus on which specification(s) of factors in (3) comprise a satisfactory test. Therefore, Exhibit 11 summarizes information from 288 regressions across each of the nine alternative lag lengths and 32 distinct specifications and reports the average coefficients across all models, Column $1 ;^{11}$ the average coefficients given the subset of models with R-squared values within 0.75 of the greatest Rsquared statistic among the 288 models, Column $2 ;^{12}$ the total fraction of coefficients with tstatistics greater than 1.96, Column 3; and the average R-squared value of all regressions that include the variable of interest, Column 4.

The basic story is that term structure momentum does not appear to load meaningfully on common risk measures - indeed no specification captures substantial variation in returns from

\footnotetext{
${ }^{10}$ Asness et al. (2009) consider a similar set of variables to measure value as well as momentum risk loadings.

${ }^{11}$ The assessment of common risk exposure under model uncertainty follows the general principles of extreme bound analysis (Leamer, 1983). The set of "free variables" that enter every regression includes the contemporaneous S\&P 500 return, gold and oil price changes (percent), the surprise component of non-farm payroll releases. The "doubtful" variables are organized with respect the dimensions of risk previously discussed.

Regarding risky asset returns (and in addition to the S\&P 500 return), these include either the one-month lagged (i.e., $t-1) \mathrm{BBB}$ corporate spread relative to Treasuries or its contemporaneous change; the set of liquidity proxies include lagged or contemporaneous changes in 3-month TED spreads, 1-month A2P2 spreads, and 10-year Treasury on-the-run premiums; and uncertainty measures include the lagged or contemporaneous changes in the VIX and the MOVE indices of option-implied volatility. In addition, although not a proxy for common risk per se, to gauge the possible conditional nature of momentum returns to market states, the analyses also include lagged or contemporaneous values of the return on the Barclays U.S. Treasury index and an indicator variable equal to one if the return on the Barclays U.S. Index is positive for the month. All in all, there are 32 alternative specifications for each of the nine look-back windows (i.e., given some specification uncertainty with respect to not only the right- but the left-hand side of the regressions), for a total of 288 models.

${ }^{12}$ This general procedure, rather than specific threshold, follows Granger and Uhlig (1990).
} 
the strategy, as the greatest R-squared value listed in Column 4 is about $0.086 .{ }^{13}$ With respect to general dimensions of risk, if anything, term structure momentum appears to hedge key exposures, more so than a benchmark Treasury portfolio. The average coefficient on the contemporaneous $\mathrm{S} \& \mathrm{P} 500$ return is negative and corresponds to about a 1.5 basis point per month increase in momentum returns with every percentage point decline in stock prices. ${ }^{14}$ However, the estimates are only statistically significant (at the 95 percent confidence level) in about 47 percent of the regressions. Also, the coefficients on lagged and contemporaneous changes in BBB spreads are largely not robust and statistically insignificant from zero, and the coefficient on non-farm payroll surprises is quite small (i.e., about 0.058 basis points for a 2standard-error shock to the series) and only significant in about 11 percent of the regressions. Momentum returns are clearly uncorrelated with percentage changes in either oil or gold prices.

Changes in one-month A2P2 spreads, which perhaps also capture some aspects of liquidity risk in addition to (near-term) corporate exposure, are statistically significant in a third of the regressions. Yet again, the weighted-average coefficient is positive, consistent with the inference that momentum returns do not increase, and may even decrease, risk exposure along this dimension, broadly consistent with the previous results with respect to other asset classes (e.g., Ilmanen, 2011; Asness et al., 2013; Moskowitz, 2012). However, an alternative measureeither the contemporary change or level value of Treasury on-the-run premiums-indicates no

\footnotetext{
${ }^{13}$ Besides these sensitivity analyses, less rigorous pairwise correlations of both the long-only and long-short momentum portfolio returns suggest, again if any relations, favorable risk exposures to factors. These results are available on request.

${ }^{14}$ Insofar as negative correlations between momentum returns and the S\&P 500 are conditioned on Treasury market returns, momentum provides an additional hedge to the risky asset beyond the general allocation to the "risk-free asset."
} 
relation, and neither the remaining liquidity proxies nor the implied volatility measures appear to be a robust correlate of momentum. ${ }^{15}$

\section{Are Momentum Returns Conditional on Ex Ante Factors?}

Variation in momentum returns remains largely unexplained and does not load unfavorably on broad risk metrics. Besides this general concern, a particularly relevant question for practitioners is whether there are ex ante identifiable conditions under which the strategy produces abnormal returns. There are at least two considerations under this rubric-first, whether abnormal returns are market state-dependent; and second, whether the magnitude of abnormal returns relates to the underlying size of the momentum signal.

Regarding the first issue of state-dependence, returns on the Barclays U.S. Treasury Index, and to a lesser extent an indicator variable for positive returns, generate fairly robust results, at least for contemporaneous values. As Exhibit 11 indicates, the weighted-average coefficients are significant in about 72 and 15 percent of the regressions, respectively, and the estimates suggest that a 1 percent return on the Barclays Index corresponds to about a 7 basis point increase in momentum returns, which seems economically meaningful. However, this result does not connote either common risk exposure per se or diminished alpha, but rather suggests that abnormal momentum returns might be conditional on market states and indicative of investor over-confidence (with respect to private views) and self-recognition bias (e.g., Daniel et al., 1998).

The degree of conditionality matters for interpretation as well as implementation, and the coefficients are only in part consistent with the existing literature on market states and momentum in individual stock returns. In contrast to Cooper et al. (2004), who examine shares,

\footnotetext{
${ }^{15}$ To test for seasonality, the inclusion of dummy variables for each month, with January as the omitted condition, does not produce any statistically significant results.
} 
momentum profits increase only with contemporaneous rather than lagged values of Treasury market returns, as the dummy variable and continuous specifications for $t-1$ are safely statistically insignificant. ${ }^{16}$ Therefore, the conditioning information with respect to broader market conditions seems of limited use for practitioners, and these results perhaps cast some doubt over a particular behavioral mechanism behind momentum profits. In other words, if only contemporaneous correlation is remotely significant, investors' over-confidence and selfattribution bias may have somewhat limited impact in the U.S. Treasury market, and perhaps particularly in a duration-neutral context, compared to other cognitive biases.

With respect to the second issue, the formation of the momentum portfolios insures that the allocation for each observation has the greatest prior return over the given lag length, again subject to the duration constraints. However, also germane to any empirical test based on attributed-sorted portfolios, the unconditional returns reported in Section 4 do not incorporate the size of the underlying momentum signal in a continuous manner, despite the use of linear programming as opposed to ordinal signal rankings. In other words, the difference between the prior return on the momentum portfolio and the return on the market allocation can vary meaningfully over the sample, and the results do not capture whether the (relative) magnitude of momentum for a given observation correlates with the size of subsequent abnormal returns. Following intuition, the relation should be positive, just as, say, the more "value" an individual share has or the greater its beta, the greater its subsequent (required or abnormal) return. ${ }^{17}$

To gauge the impact, the regressions also include a measure of relative magnitude, namely the excess prior return of the momentum portfolio compared to the market portfolio for each alternative lag length. In short, as noted in Exhibit 11, apart from the 5-month lag, which is

\footnotetext{
${ }^{16}$ Cooper et al. (2004) present estimates using lagged returns over 12-, 24-, and 36-month intervals.

${ }^{17}$ For a general critique of attribute-sorted portfolios, see Ferson (1996).
} 
perversely negative, none of the coefficients (i.e., on "Signal Size") are statistically significant from zero in any regression. This finding is perhaps puzzling, in that greater relative momentum does not correspond to greater abnormal returns, as well as disappointing for practitioners, as the data do not produce a conditioning ex ante factor that indicates just when to follow the strategy (i.e., when the prior return on the momentum portfolio meaningfully exceeds the prior return on the index).

\section{Momentum and Gaussian Arbitrage-free Affine Term Structure Models}

Even if returns to the strategy do not load meaningfully on common risk proxies, another consideration regarding this particular asset class is whether momentum in government bond markets embeds some information about risks along the term structure captured by arbitrage-free models. ${ }^{18}$ The issue is not necessarily whether momentum somehow captures violations of arbitrage along the yield curve, and again by construction the strategy is insensitive to parallel shifts, but rather whether abnormal returns compensate investors for taking duration risk at various points along the curve, which broad measures such as an international CAPM are unlikely to gauge. In other words, and also broadly germane to the cross-sectional results in Asness et al. (2013) as well as the time-series findings in Moskowitz et al. (2012), ${ }^{19}$ does the duration-neutral momentum strategy simply reflect forward term premiums? The quick answer is only to a limited degree that does not fully explain the abnormal returns reported previously, caveats aside regarding GATSMs and the accuracy of arbitrage-free estimation of duration risk.

To begin the longer answer, standard GATSMs afford estimates of forward instantaneous term premiums at any point on the curve, of course including the (midpoints of the) six duration

\footnotetext{
${ }^{18}$ See Vasicek (1977) or references in, say, Kim and Wright (2005).

${ }^{19}$ That is, it could be that cross-market momentum reflects higher term premiums in some markets, namely past winners, as opposed to others, past losers (Asness et al, 2010), and therefore the observed pattern is not anomalous. Similarly, time-series momentum might coincide with persistently elevated term premiums within a given market (Moskowitz et al., 2012).
} 
buckets for the Barclays index used to construct the momentum portfolios. Given any preference for aggregate portfolio duration, a GATSM-based schedule of term premiums in effect shows where along the curve investors receive the greatest compensation for bearing the desired degree of interest rate risk. For example, Exhibit 12 shows recent estimates of forward instantaneous term premiums through the 10 -year horizon, ${ }^{20}$ and roughly speaking for the most recent Kim and Wright (2005) results (the solid black line), term premiums are greater at the very front and back ends of the term structure than at intermediate maturities. Therefore, for a given portfolio duration, say perhaps 3 years for the sake of illustration, the required or expected return on a barbell appears less than for a bulleted position. ${ }^{21}$

A natural question is whether such signals from a GATSM on average produce excess returns. ${ }^{22}$ Consider two tests. The first is to estimate returns from a duration-neutral and longonly GATSM-based strategy, following a design similar to the formation of momentum portfolios outlined in Section 3, and use those returns as a benchmark for momentum. Akin to (1) and (2), this test comprises evaluating portfolios with the greatest weighted-average forward term premium at each sample observation, under the constraints that the weights produced a duration-neutral allocation with respect to the benchmark, again with no short sales. Note that to incorporate possible sensitivity of GATSMs to sample selection — particularly given recent data

\footnotetext{
${ }^{20}$ The GATSM used in this application is an extended three-factor Vasicek (1977) model (which does not use any survey information on expected short rates) based on

$$
d X_{t}=\kappa\left(\eta-X_{t}\right) d t+\Sigma d Z_{t}
$$

where $X$ is the vector of underlying latent factors, $\kappa$ is the matrix of mean-reversion parameters, $\eta$ is the vector of long-run means of $X, \Sigma$ is the matrix of volatility parameters, and $d Z$ is the Brownian motion increment. For further background, see Kim and Wright (2005) or Langeteig (1980).

${ }^{21}$ Put another way, given any active view on duration with respect to parallel curve shifts, but indifference to curve position, forward instantaneous term premiums indicate where along the term structure to invest in order to reap the most reward per unit of (short-term interest rate) risk.

${ }^{22}$ Recent literature raises a number of questions about GATSMs, beyond the lack of consensus on the exact stochastic process for the underlying factors. For example, and besides the most recent problematic experience near the zero lower bound for nominal interest rates, the analyses in Hamilton and $\mathrm{Wu}$ (2012) raise questions about GATSM-based forecasts.
} 
that includes the global financial crisis (Durham, 2013) and indeed as evidenced by the wide range of both the level and slopes of forward term premium schedules in Exhibit 12 - the following analyses use models with parameters estimated from data beginning in April 1991 but ending alternatively in July 2008, 2009, 2010, 2011, and 2012 (i.e., five alternative samples).

Exhibit 13 summarizes the results from the strategy, and indeed excess returns are positive, on the order of between 14 to 100 basis points, depending on the affine model sample, with information ratios that are smaller compared to momentum returns and a $\mathrm{t}$ statistic less than standard critical values for the model estimated with data ending in 2010 (Column 3). These results are neither surprising nor comprise "abnormal" returns if the GATSM has some validity, given that each portfolio by construction has the greatest estimated ex ante compensation for duration risk possible under the constraints.

In short, simple regressions of momentum returns (e.g., from Exhibits 1 and 2) on these GATSM-portfolio returns should produce additional information about the alpha and beta of the anomaly. Simple OLS regressions follow

$$
r_{M O M(t, n)}=\alpha+\beta r_{\operatorname{GATSM}(t, j)}+\varepsilon_{t}
$$

where $r_{M O M, t}$ is the excess momentum return, $r_{G A T S M, t}$ is the excess return from the term premium portfolio, and $\varepsilon_{t}$ is the error term, with separate regressions for the $n^{\text {th }}$ (nine) momentum windows and $j^{\text {th }}$ (five) GATSM samples, for a total of 45 different specifications. According to this method, momentum does seem to load on forward-term-premium-based portfolios, but incompletely so. The R-squared values indicate that GATSM returns account for about 37 percent of the variation of the anomaly on average, which implies some modest loading. And turning to the coefficients, every beta is less than one, with an average of about 0.606 , and the full distribution of statistics is reported in Exhibit 14. More important, the alphas in Exhibit 15 
are largely positive, with an average of about 5.25 basis points (per month), as the mean $t$ statistic across the 45 regressions is about 2.14 , which suggests reasonable statistical significance. Therefore, momentum returns appear to be "low beta, positive alpha" and as such remain abnormal.

A second test under this rubric is perhaps more precise and draws from the notion that, following Adrian et al. (2013a, 2013b) and just as in the case of the CAPM, a GATSM can be represented by a regression of returns on the pricing kernel, if it is an affine function of the underlying factors. Therefore, rather than form portfolios and calculate GATSM-based returns, an alternative to (4) is simply to regressing momentum returns on, say, the contemporaneously observed principal components of the term structure - approximately level, slope, and curvature. Similar to (4), the intercept of these regressions should be insignificant if the momentum anomaly fully loads on the term structure.

But yet again, the results similarly suggest positive alphas and modest loadings. For example, Exhibit 16 summarizes the results for nine regressions (again one for each lag assumption) using long-only returns, and the average alpha is about 15.63 basis points, with a mean $t$ statistic of about 2.13. The corresponding $t$ statistics for the first and second, but not the third, principal components are statistically insignificant. Although the results suggest some loading on curvature, the average R-squared value is quite low, at about 0.01. Similarly, Exhibit 17 shows the corresponding estimates for the long-short strategy, and the alphas are similarly sizeable, with a mean of about 21.67 basis points, and statistically significant, with an average $t$ statistic of about 1.98. Notably, the loadings on all three principal components are statistically insignificant with the relaxation of the short selling constraint, and again the R-squared statistic suggests that the model accounts for minimal variation in momentum returns. 
Therefore, both of these tests broadly suggest that momentum represents more than sufficient compensation for "curve risk," with the remaining return possibly owing to some cognitive shortcomings among market participants or inefficiencies that trace to bounded rationality among heterogeneous investors. However, some caveats apply with any GATSMbased test, especially with respect to the first method. For example, any assessment of momentum returns in effect comprises its own back test, given that no sample estimates per se are required, just simple linear-programming using past returns. By contrast, the formation of the GATSM-based portfolios fully comprises an in-sample exercise. The estimation of the GATSM parameters as well as the projection of the underlying factors, crucial in the estimation of term premiums, use information from most of the period over which returns are observed. Also, the GATSMs might be mis-specified, although the first three principal components arguably capture the term structure reasonably, and the GATSM portfolio sample sensitivity analysis might go some way toward addressing some concerns about parameter stability.

No analyses can unequivocally establish that term structure momentum returns do not comprise risk compensation along some dimension. Indeed, at an extreme, one could argue that momentum returns must somehow capture the true, unobservable forward term premium that flawed GATSMs fail to identify. Even so, the fact that such simple duration-neutral trading rules load as they do on standard GATSM-based term premiums - with sizeable unexplained variance, betas less than one, and positive alphas - perhaps provide some comfort that abnormal returns do not represent purely statistical artifacts.

\section{Discussion: Portfolio Formation and Caveats}

Evidence of momentum along the U.S. Treasury term structure may be as compelling as similar price history findings in other asset classes. Abnormal returns are sizeable (especially 
relative to tracking error), duration-neutral, positively skewed, uncorrelated with common risk factors, and appear to have positive alphas and less-than-one betas with respect to strategies that are long estimated forward term premiums.

Indeed, some initial discussion of portfolio formation is warranted. ${ }^{23}$ The most obvious application is to follow the cross-sectional curve momentum strategy exclusively. However, there are numerous possible sources of abnormal returns, including “time-series" momentum and/or a broad "value" approach. With respect to the first, again the preceding reported anomaly traces to relative returns given the cross-section of the term structure, under the duration-neutral constraint. However, consider the results in Moskowitz et al. (2012), which suggest significant time-series momentum in aggregate market returns. If U.S. Treasury index returns are indeed persistent with respect to prior returns from one to 12 months, such information embeds signals about optimal overall duration - that is, (auto-correlated) parallel shifts. In short, the crosssectional portfolios reported previously, in combination with the implied time-series patterns from Moskowitz et al. (2012), might imply a comprehensive active position on curve as well as duration based on momentum anomalies.

Regarding the second, besides a simple metric of real yields (e.g., Asness et al., 2013), Treasury market participants have a number of formal tools at their disposal, including possible violations of arbitrage along the term structure based on GATSMs; fair-value assessments from simple reduced-form models of yields, perhaps with respect to investors' expectations for fundamentals such as expected inflation and real GDP growth and other variables (following a

\footnotetext{
${ }^{23}$ Besides implications for investors, insofar as momentum reflects (interest rate) risk compensation or, in other words, the schedule of term premiums, observing such patterns might contain some information relevant for monetary policy makers with comparatively less confidence in GATSMs. As an example, Exhibit 4 shows that momentum portfolios have been concentrated at the front and toward the back end of the term structure, which concomitantly implies that required compensation, again to abandon the anomalous interpretation of the data, was less pronounced nearer the belly of the curve. In short, this configuration is broadly consistent with the view that Federal Reserve large scale asset purchases and the maturity extension program succeeded in lower term premiums particularly at intermediate maturities during the period.
} 
rules-based framework for monetary policy and interest rates); and of course active views on the direction of the state vector itself, most prominently including macroeconomic forecasts.

Therefore, a more powerful strategy would be to combine momentum and growth, if indeed the distinct approaches each produce positive alpha and are imperfectly correlated. Ideally, investors might trace out the full (mean-variance or tracking-error) efficient frontier of the two "assets" and select the combination of strategies that corresponds to a given risk preference. Or, absent complete expected return vectors for both approaches, a related alternative might be to construct the tracking-error efficient frontier of value portfolios—not visà-vis a Treasury market index, but with respect to the optimal momentum portfolio. Depending on the magnitude of the tracking error constraint, ex ante relative risk bands would ground valuebased active views toward the momentum portfolio. ${ }^{24}$

But before application for investors gets too far afield, further research on term structure or curve momentum patterns would be useful, given lingering questions about the precise behavioral mechanism(s) that produce abnormal returns in government bond markets. ${ }^{25}$ As previously discussed, over-confidence and self-attribution bias might not play as large a role as in equity markets, given that these results are only consistent with the conditionality of contemporaneous, rather than lagged, market states. In addition, other mechanisms are arguably more difficult to pin down, as opposed to, say, the market for small-cap stocks. For instance, previous studies report manifestations of the "disposition effect" using market quotes and data on

\footnotetext{
${ }^{24} \mathrm{An}$ (M-GARCH, say) estimate of variance-covariance of the term structure as well as the expected return vector for the value strategy are still required inputs for this alternative.

${ }^{25}$ Unfinished work does not solely entail developing more persuasive behavioral theories. In addition to better assessment of alpha and beta with respect to term premiums, the question of momentum frequency is perhaps particularly relevant with regard to Treasuries, especially given previous evidence using intraday data that suggests market participants very quickly absorb information (e.g., data releases and Federal Reserve policy announcements). For example, see Balduzzi et al., 2001. An additional issue is that in contrast to the apparent close relation between equity price and earnings momentum, there is no such obvious link between persistence in the direction of broader macroeconomic news releases or monetary policy surprises, which are highly relevant to the term structure.
} 
mutual fund holdings of individual shares (Frazzini, 2006) as well as neural experiments (Frydman et al., 2013), but reference prices for nominal U.S. Treasuries along the curve are arguably more difficult to detect. Then again, previous studies document persistent returns in foreign exchange and commodities, markets which are presumably no less efficient and perhaps just as deep. Also, in general and germane to any financial asset class, behavioral approaches remain some way from satisfactorily accounting for all phenomena that the efficient markets hypothesis cannot explain (e.g., Fama, 1998). 
Exhibit 1

Returns to Duration-Neutral Nominal U.S. Treasury Momentum Strategy:12-Month Lag Average Annual Return (bps): (95.8967), Tracking Error (bps) (149.5041), Info. Ratio: (0.64143)

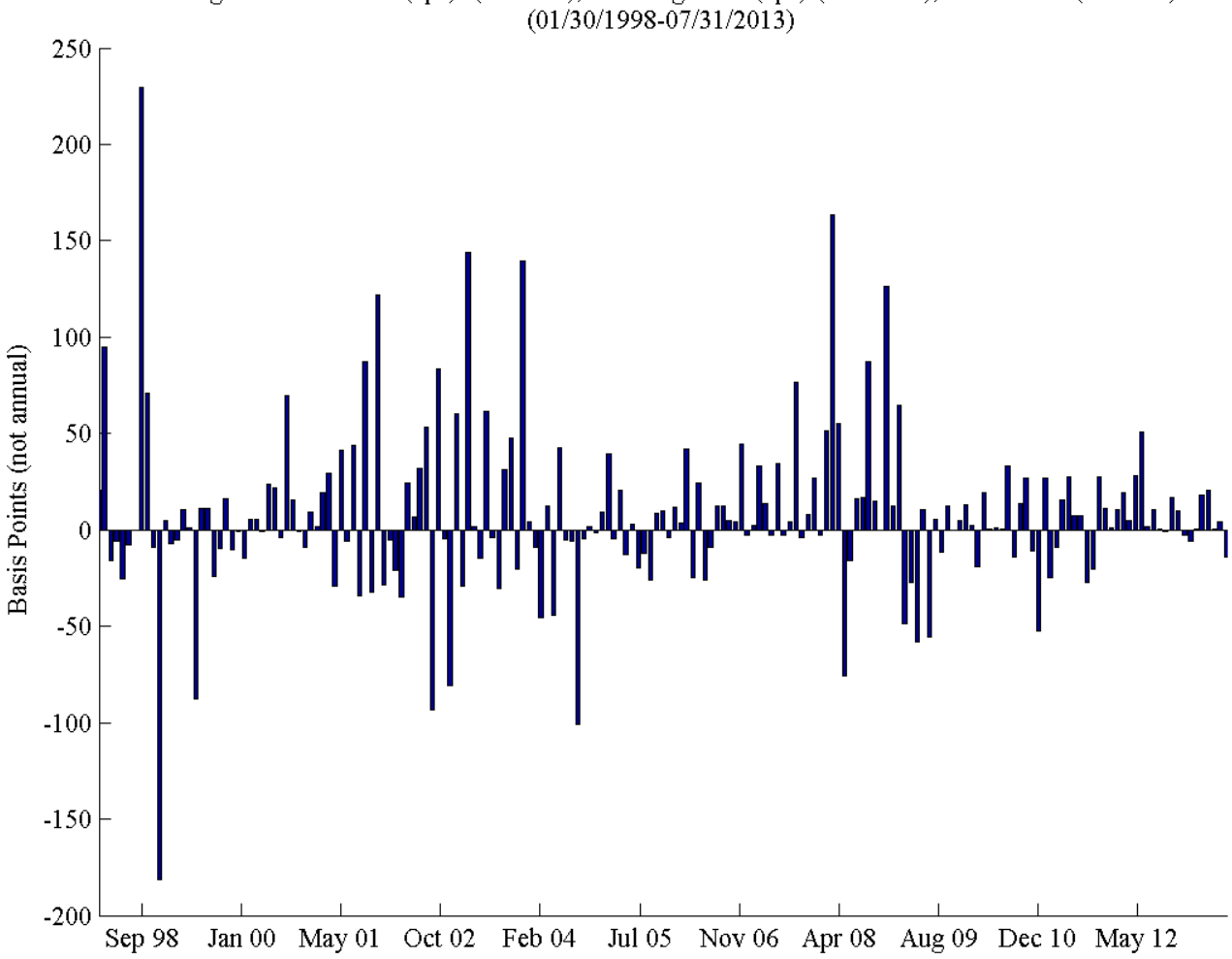

Exhibit 2

Distribution of Excess Returns on Duration-Neutral Nominal U.S. Treasury Momentum Strategy:12-Month Lag Average Annual Return (bps): (95.8967), Skewness (0.88949), Octile Skewness: (0.15769)

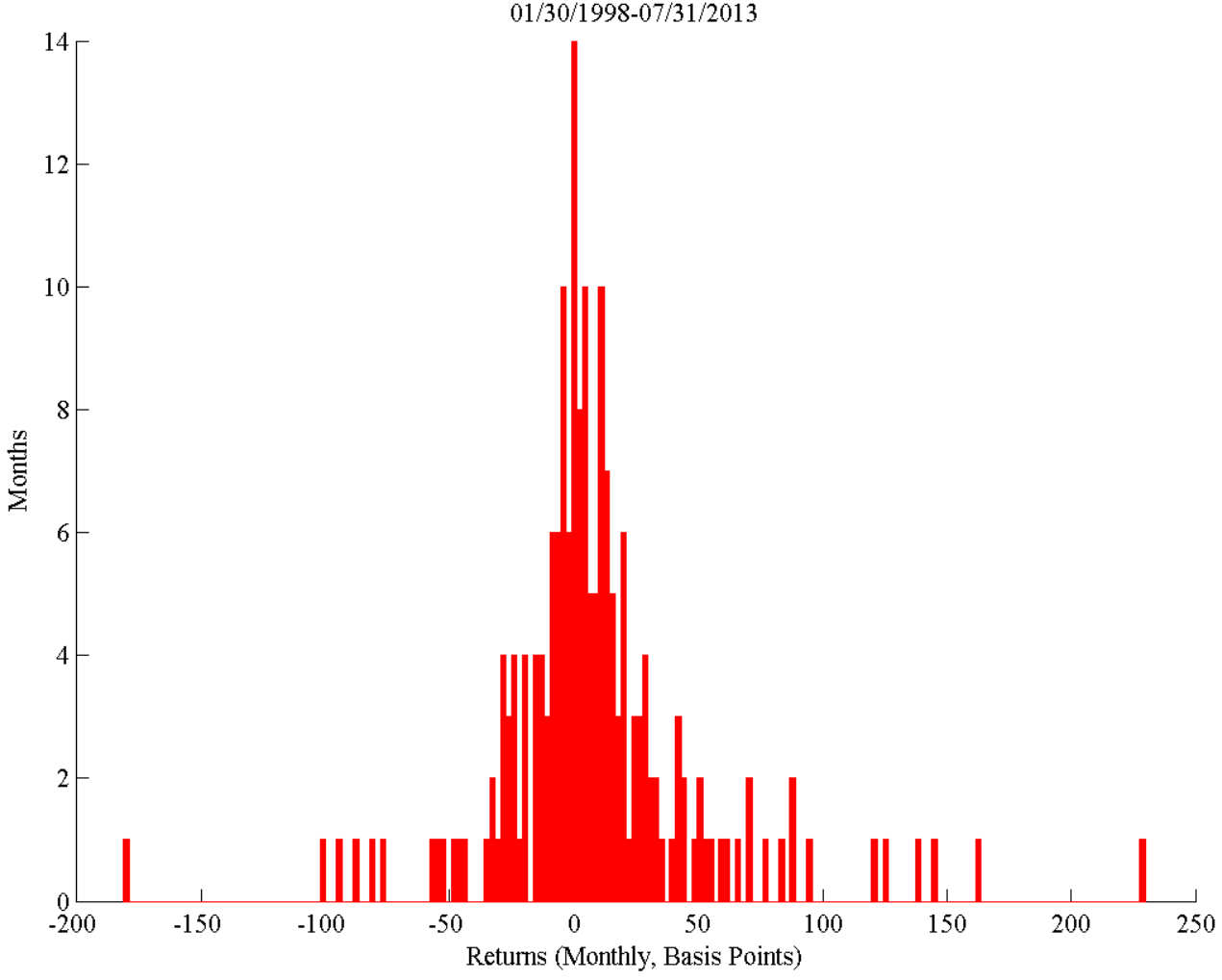


Exhibit 3

Results: Duration-Neutral Nominal Government Bond Momentum Strategy US

\begin{tabular}{|c|c|c|c|c|c|c|c|c|c|}
\hline & $-1-$ & $-2-$ & $-3-$ & $-4-$ & $-5-$ & $-6-$ & $-7-$ & $-8-$ & $-9-$ \\
\hline Lag Window (Months) & 5 & 6 & 7 & 8 & 9 & 10 & 11 & 12 & 13 \\
\hline Ave. Annual Return (bps) & 54.2361 & 108.365 & 103.6823 & 100.2319 & 120.2436 & 112.2904 & 103.4671 & 95.8967 & 77.5382 \\
\hline Tracking Error & 142.616 & 144.8703 & 146.01 & 147.2297 & 152.7846 & 147.7993 & 146.9927 & 149.5041 & 141.6877 \\
\hline Information Ratio (IR) & 0.38029 & 0.74801 & 0.7101 & 0.68079 & 0.78701 & 0.75975 & 0.70389 & 0.64143 & 0.54725 \\
\hline IR T-Statistic & 5.2969 & 10.3917 & 9.8395 & 9.4087 & 10.8482 & 10.4448 & 9.6513 & 8.7714 & 7.4635 \\
\hline Skewness & 0.77477 & 0.36309 & 1.149 & 1.1744 & 0.78456 & 0.9958 & 0.91968 & 0.88949 & 0.9503 \\
\hline Octile Skewness & 0.23461 & 0.24931 & 0.25345 & 0.24425 & 0.17305 & 0.22475 & 0.14503 & 0.15769 & 0.19921 \\
\hline$\%$ Excess Returns $>0$ & 50.5155 & 58.0311 & 59.375 & 56.5445 & 60 & 58.2011 & 59.0426 & 59.3583 & 56.4516 \\
\hline Mean Turnover (per month) & 0.32269 & 0.3407 & 0.24528 & 0.25535 & 0.21899 & 0.1361 & 0.167 & 0.1657 & 0.13716 \\
\hline Bid-Ask Significance Threshold (bps) & 8.8236 & 21.506 & 28.2089 & 25.8968 & 37.4899 & 55.8531 & 41.1444 & 37.4521 & 34.7366 \\
\hline Ave. Rel. Weight: $1-3$ yrs & -0.10648 & -0.11593 & -0.13139 & -0.14176 & -0.15375 & -0.16559 & -0.17128 & -0.15511 & -0.14022 \\
\hline Ave. Rel. Weight: $3-5$ yrs & -0.053626 & -0.05514 & -0.039883 & -0.034278 & -0.033043 & -0.018057 & 0.0010538 & -0.0091802 & -0.023829 \\
\hline Ave. Rel. Weight: 5-7 yrs & 0.18353 & 0.19506 & 0.20355 & 0.21344 & 0.21505 & 0.21567 & 0.19353 & 0.18 & 0.17434 \\
\hline Ave. Rel. Weight: 7-10 yrs & 0.048268 & 0.052258 & 0.048048 & 0.040611 & 0.054626 & 0.050056 & 0.056416 & 0.056978 & 0.057109 \\
\hline Ave. Rel. Weight: $10-20$ yrs & -0.046964 & -0.047278 & -0.053984 & -0.046488 & -0.044326 & -0.041725 & -0.03493 & -0.030199 & -0.025459 \\
\hline Ave. Rel. Weight: $20+$ yrs & -0.024725 & -0.028974 & -0.02634 & -0.03153 & -0.038553 & -0.04035 & -0.044788 & -0.042494 & -0.041945 \\
\hline Sample Start & 06/30/1997 & $07 / 31 / 1997$ & 08/29/1997 & 09/30/1997 & 10/31/1997 & $11 / 28 / 1997$ & $12 / 31 / 1997$ & 01/30/1998 & $02 / 27 / 1998$ \\
\hline Sample End & $07 / 31 / 2013$ & $07 / 31 / 2013$ & $07 / 31 / 2013$ & $07 / 31 / 2013$ & $07 / 31 / 2013$ & $07 / 31 / 2013$ & $07 / 31 / 2013$ & $07 / 31 / 2013$ & $07 / 31 / 2013$ \\
\hline
\end{tabular}




\section{Exhibit 4}

Duration-Neutral Nominal U.S. Treasury Momentum Strategy (12-Month Lag) 01/31/2012-07/31/2013

Barclays Index Maturity Buckets: (1) 1-3 year (2) 3-5 year (3) 5-7 year

(4) $7-10$ year (5) $10-20$ year (6) $20+$ years

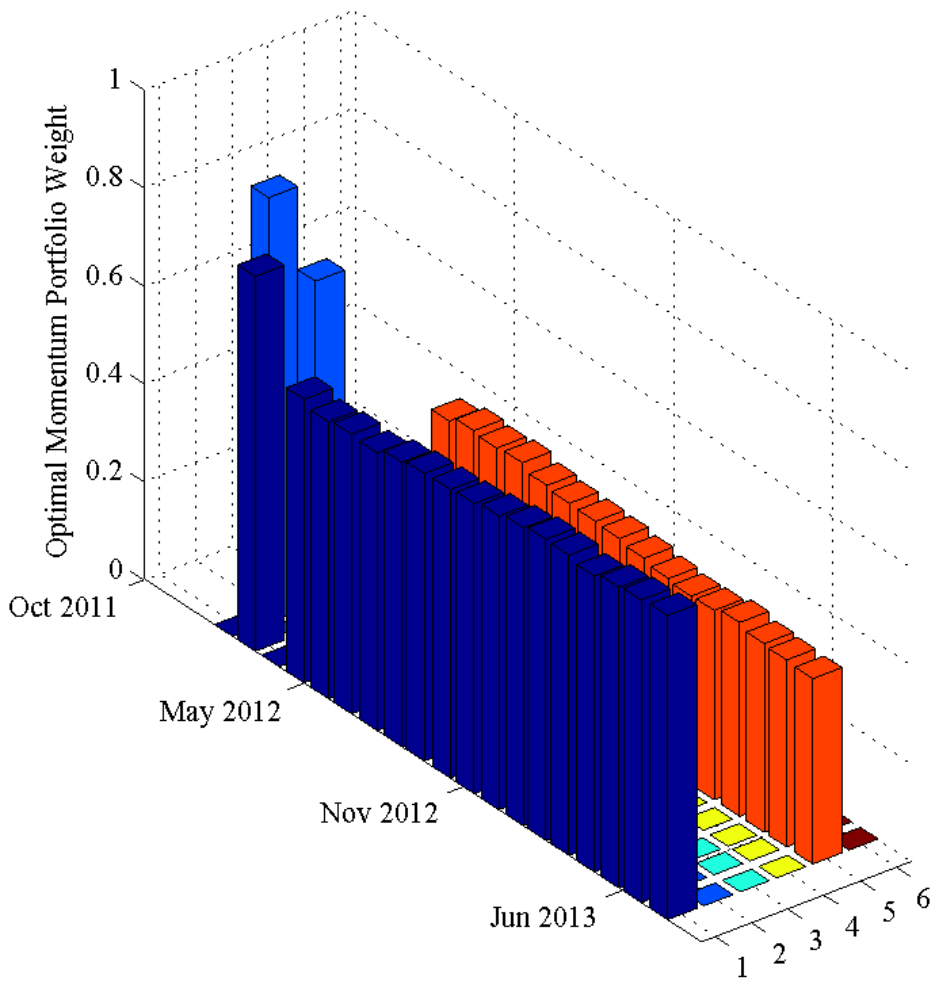

Maturity Buckets 
Exhibit 5

Returns to Long-Short, Zero-Duration Nominal U.S. Treasury Momentum Strategy:12-Month Lag Average Annual Return (bps): (206.5239), Tracking Error (bps) (203.9666), Info. Ratio: (1.0125)

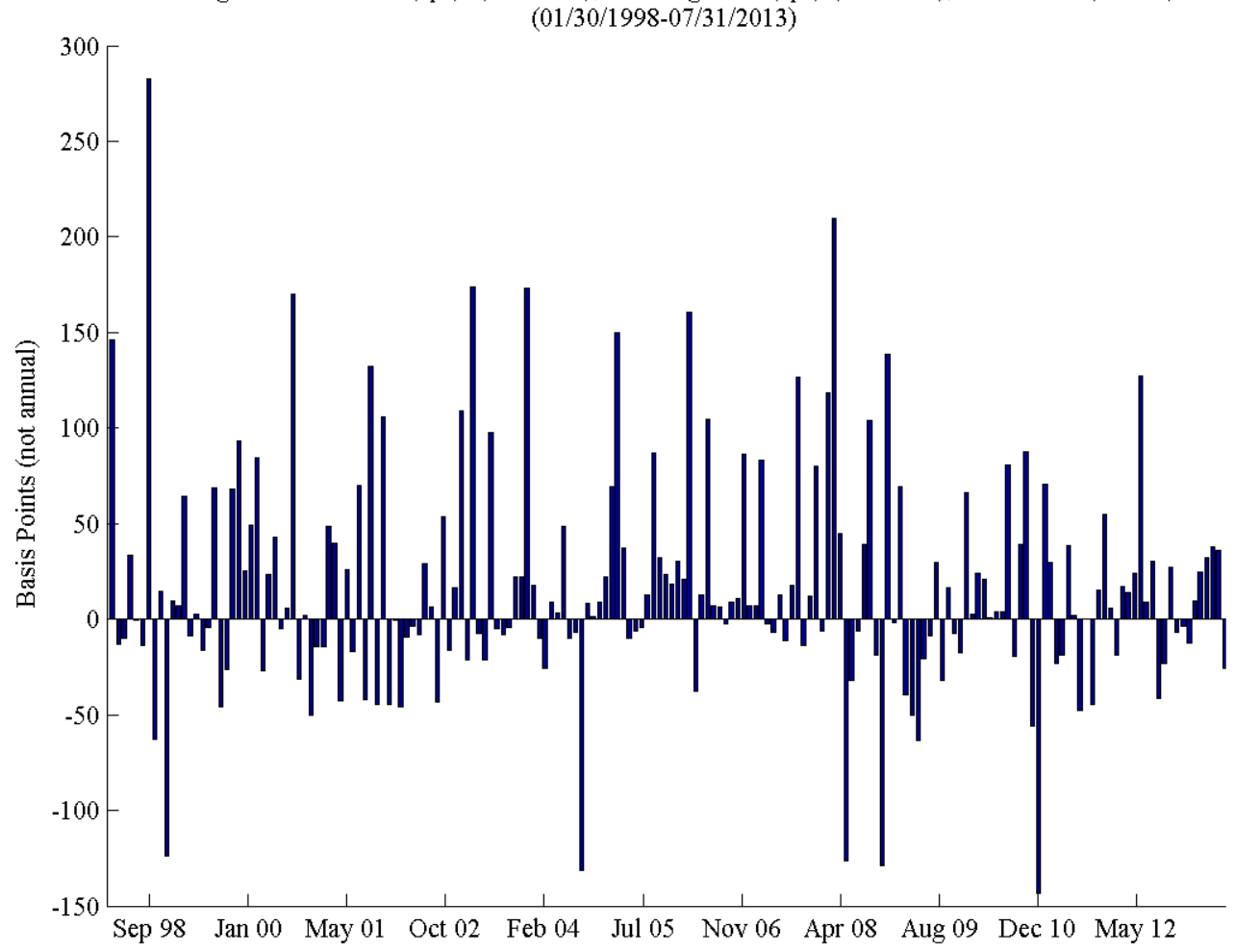

\section{Exhibit 6}

Distribution of Excess Returns on Long-Short, Zero-Duration Nominal U.S. Treasury Momentum Strategy:12-Month Lag Average Annual Return (bps): (206.5239), Skewness (0.95092), Octile Skewness: (0.32468)

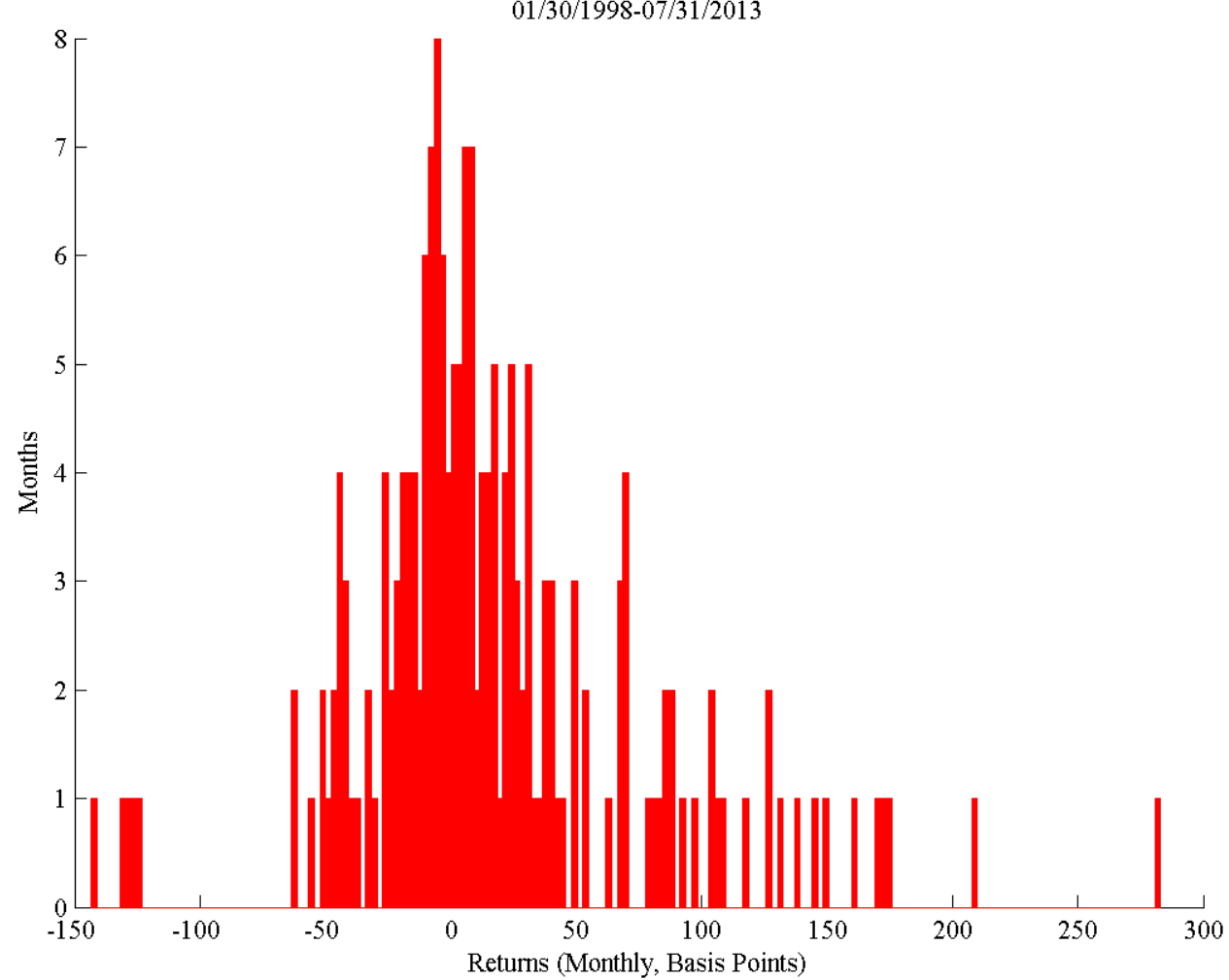


Exhibit 7

Results: (Long-Short) Zero Duration Nominal Government Bond Momentum Strategy US

\begin{tabular}{|c|c|c|c|c|c|c|c|c|c|}
\hline & $-1-$ & $-2-$ & $-3-$ & $-4-$ & $-5-$ & $-6-$ & $-7-$ & $-8-$ & $-9-$ \\
\hline$\overline{\text { Lag Window (Months) }}$ & 5 & 6 & 7 & 8 & 9 & 10 & 11 & 12 & 13 \\
\hline Ave. Annual Return (bps) & 91.2271 & 200.9467 & 198.1338 & 158.9528 & 175.6175 & 161.3137 & 173.5224 & 206.5239 & 174.8624 \\
\hline Tracking Error & 219.4796 & 232.9664 & 227.5775 & 224.7348 & 225.2291 & 215.9808 & 214.1228 & 203.9666 & 192.577 \\
\hline Information Ratio (IR) & 0.41565 & 0.86256 & 0.87062 & 0.70729 & 0.77973 & 0.74689 & 0.81039 & 1.0125 & 0.90801 \\
\hline IR T-Statistic & 5.7894 & 11.983 & 12.0637 & 9.7749 & 10.7478 & 10.268 & 11.1115 & 13.8463 & 12.3836 \\
\hline Skewness & 0.4614 & 0.33964 & 0.77113 & 0.84431 & 0.56576 & 0.73215 & 0.66506 & 0.65755 & 0.90711 \\
\hline Octile Skewness & 0.13202 & 0.3275 & 0.35603 & 0.25268 & 0.27554 & 0.25936 & 0.19289 & 0.32468 & 0.24768 \\
\hline$\%$ Excess Returns $>0$ & 56.701 & 59.0674 & 57.2917 & 59.1623 & 58.4211 & 57.1429 & 61.1702 & 57.754 & 56.4516 \\
\hline Mean Turnover (per month) & 0.63496 & 0.62434 & 0.45357 & 0.50325 & 0.44416 & 0.37192 & 0.39338 & 0.34935 & 0.30688 \\
\hline Bid-Ask Significance Threshold (bps) & 9.339 & 24.0932 & 32.608 & 22.8633 & 28.8735 & 31.4231 & 32.3074 & 44.152 & 41.9544 \\
\hline Ave. Rel. Weight: $1-3$ yrs & 0.015061 & -0.0022552 & -0.0052234 & -0.0055237 & -0.012757 & -0.008462 & -0.036479 & 0.014143 & 0.025999 \\
\hline Ave. Rel. Weight: 3-5 yrs & 0.021273 & 0.013324 & 0.036772 & 0.046907 & 0.04461 & 0.053584 & 0.063731 & 0.020173 & 0.020307 \\
\hline Ave. Rel. Weight: 5-7 yrs & -0.074802 & -0.061179 & -0.085352 & -0.10008 & -0.097824 & -0.10638 & -0.085577 & -0.10484 & -0.114 \\
\hline Ave. Rel. Weight: 7-10 yrs & 0.0011267 & 0.024187 & 0.02742 & 0.024001 & 0.029599 & 0.017481 & 0.019519 & 0.01528 & 0.0014437 \\
\hline Ave. Rel. Weight: $10-20$ yrs & 0.041896 & 0.043809 & 0.038404 & 0.050763 & 0.062908 & 0.066027 & 0.075678 & 0.081654 & 0.089271 \\
\hline Ave. Rel. Weight: $20+$ yrs & -0.0045536 & -0.017886 & -0.012021 & -0.016069 & -0.026536 & -0.022247 & -0.036872 & -0.026408 & -0.023026 \\
\hline Sample Start & 06/30/1997 & 07/31/1997 & 08/29/1997 & 09/30/1997 & $10 / 31 / 1997$ & $11 / 28 / 1997$ & $12 / 31 / 1997$ & 01/30/1998 & 02/27/1998 \\
\hline Sample End & $07 / 31 / 2013$ & $07 / 31 / 2013$ & $07 / 31 / 2013$ & $07 / 31 / 2013$ & $07 / 31 / 2013$ & $07 / 31 / 2013$ & $07 / 31 / 2013$ & $07 / 31 / 2013$ & $07 / 31 / 2013$ \\
\hline
\end{tabular}


Exhibit 8

Results: Duration-Neutral Nominal Government Bond Momentum Strategy

Japan

\begin{tabular}{|c|c|c|c|c|c|c|c|c|c|}
\hline & $-1-$ & $-2-$ & $-3-$ & $-4-$ & $-5-$ & $-6-$ & $-7-$ & $-8-$ & $-9-$ \\
\hline Lag Window (Months) & 5 & 6 & 7 & 8 & 9 & 10 & 11 & 12 & 13 \\
\hline Ave. Annual Return (bps) & 22.9017 & 30.6473 & 20.241 & 18.7053 & -5.9823 & 9.6769 & 9.1666 & 12.4794 & 5.3367 \\
\hline Tracking Error & 68.3283 & 69.3996 & 70.8881 & 73.0272 & 73.1321 & 74.5657 & 74.9327 & 73.9395 & 74.5652 \\
\hline Information Ratio (IR) & 0.33517 & 0.44161 & 0.28553 & 0.25614 & -0.081802 & 0.12978 & 0.12233 & 0.16878 & 0.071571 \\
\hline IR T-Statistic & 4.3701 & 5.7409 & 3.7009 & 3.3101 & -1.0539 & 1.667 & 1.5666 & 2.1548 & 0.91095 \\
\hline Skewness & -0.35353 & -0.64839 & -0.72956 & -0.49753 & -0.54949 & -0.55811 & -0.76495 & -0.8462 & -0.75001 \\
\hline Octile Skewness & 0.090509 & 0.058622 & -0.045726 & 0.05515 & 0.021887 & 0.0024816 & -0.10482 & -0.054721 & -0.053855 \\
\hline$\%$ Excess Returns $>0$ & 54.7059 & 58.5799 & 59.5238 & 56.2874 & 51.2048 & 56.9697 & 57.9268 & 57.0552 & 54.321 \\
\hline Bid-Ask Significance Threshold (bps) & 2.9571 & 5.0535 & 2.6436 & 2.5264 & -6.0984 & -0.5852 & -0.83184 & 0.44954 & -2.5796 \\
\hline Ave. Rel. Weight: $1-3$ yrs & -0.0097383 & -0.035053 & -0.036394 & -0.045256 & -0.05278 & -0.051482 & -0.053464 & -0.061843 & -0.054918 \\
\hline Ave. Rel. Weight: 3-5 yrs & -0.16443 & -0.15359 & -0.15758 & -0.15378 & -0.15739 & -0.18104 & -0.18268 & -0.18228 & -0.19121 \\
\hline Ave. Rel. Weight: 5-7 yrs & 0.17539 & 0.18792 & 0.19901 & 0.20531 & 0.22637 & 0.22624 & 0.22694 & 0.21681 & 0.2153 \\
\hline Ave. Rel. Weight: 7-10 yrs & 0.022088 & 0.03829 & 0.029971 & 0.036796 & 0.032429 & 0.064637 & 0.074052 & 0.10779 & 0.10456 \\
\hline Ave. Rel. Weight: $10-20$ yrs & 0.019171 & 0.013734 & 0.016792 & 0.0085732 & 0.0030025 & 0.0037127 & -0.0027065 & -0.012756 & -0.0033741 \\
\hline Ave. Rel. Weight: $20+$ yrs & -0.042484 & -0.051301 & -0.051805 & -0.051641 & -0.05163 & -0.062075 & -0.062137 & -0.06772 & -0.070355 \\
\hline Sample Start & 06/30/1999 & 07/31/1999 & 08/31/1999 & 09/30/1999 & $10 / 31 / 1999$ & $11 / 30 / 1999$ & $12 / 31 / 1999$ & $01 / 31 / 2000$ & $02 / 29 / 2000$ \\
\hline Sample End & $07 / 31 / 2013$ & $07 / 31 / 2013$ & $07 / 31 / 2013$ & $07 / 31 / 2013$ & $07 / 31 / 2013$ & $07 / 31 / 2013$ & $07 / 31 / 2013$ & $07 / 31 / 2013$ & $07 / 31 / 2013$ \\
\hline
\end{tabular}

Exhibit 9

Results: Duration-Neutral Nominal Government Bond Momentum Strategy

Canada

Lag Window (Months)

Ave. Annual Return (bps)

Tracking Error

Information Ratio (IR)

IR T-Statistic

Skewness

Octile Skewness

$\%$ Excess Returns $>0$

Mean Turnover (per month)

Bid-Ask Significance Threshold (bps)

Ave. Rel. Weight: 1-3 yrs

Ave. Rel. Weight: 3-5 yrs

Ave. Rel. Weight: 5-7 yrs

Ave. Rel. Weight: 7-10 yrs

Ave. Rel. Weight: 10-20 yrs

Ave. Rel. Weight: $20+$ yrs

Sample Start

Sample End

\begin{tabular}{ccc}
$-1-$ & $-2-$ & $-3-$ \\
\hline 5 & 6 & 7 \\
-1.5093 & -7.2218 & 4.0157 \\
86.6601 & 87.024 & 84.9868 \\
-0.017417 & -0.082986 & 0.047251 \\
-0.22709 & -1.0788 & 0.61245 \\
-0.41669 & -0.36165 & 0.038737 \\
0.040904 & -0.020285 & 0.11824 \\
50 & 49.1124 & 48.2143 \\
0.43446 & 0.36614 & 0.33474 \\
-2.7882 & -4.6299 & -2.1996 \\
-0.080196 & -0.082605 & -0.077616 \\
-0.13575 & -0.11234 & -0.12817 \\
0.086812 & 0.068524 & 0.068719 \\
0.15487 & 0.15677 & 0.16173 \\
0.1054 & 0.090386 & 0.10235 \\
-0.13114 & -0.12074 & -0.12701 \\
$06 / 30 / 1999$ & $07 / 31 / 1999$ & $08 / 31 / 1999$ \\
$07 / 31 / 2013$ & $07 / 31 / 2013$ & $07 / 31 / 2013$
\end{tabular}

$-4-$
8
4.9129

4.9129

88.6274

0.055433

0.71636

$-0.35382$

0.089635

49.1018

0.35639

$-1.9943$

$-0.095649$

$-0.12523$

0.075677

0.19218

0.089159

$-0.13614$

09/30/1999

07/31/2013

\begin{tabular}{ccccc}
$-5-$ & $-6-$ & $-7-$ & $-8-$ & $-9-$ \\
\hline 9 & 10 & 11 & 12 & 13 \\
26.9732 & 37.5688 & 39.7347 & 39.8814 & 13.7844 \\
83.7013 & 83.4621 & 83.1164 & 82.9674 & 83.6878 \\
0.32226 & 0.45013 & 0.47806 & 0.48069 & 0.16471 \\
4.152 & 5.782 & 6.1222 & 6.137 & 2.0964 \\
-0.084777 & 0.051846 & 0.13782 & 0.14826 & 0.13798 \\
-0.017961 & 0.0098419 & 0.01132 & 0.00025326 & 0.0019352 \\
56.6265 & 56.9697 & 56.0976 & 57.0552 & 53.0864 \\
0.28455 & 0.27653 & 0.23207 & 0.24497 & 0.23824 \\
4.1704 & 7.4837 & 9.7002 & 9.234 & 0.31381 \\
-0.11312 & -0.12368 & -0.13633 & -0.12871 & -0.12867 \\
-0.13009 & -0.13528 & -0.14523 & -0.14032 & -0.13617 \\
0.085803 & 0.094762 & 0.11617 & 0.10463 & 0.10033 \\
0.21417 & 0.22069 & 0.2575 & 0.24708 & 0.24494 \\
0.094084 & 0.10623 & 0.073048 & 0.077429 & 0.077973 \\
-0.15084 & -0.16272 & -0.16515 & -0.16012 & -0.15841 \\
$10 / 31 / 1999$ & $11 / 30 / 1999$ & $12 / 31 / 1999$ & $01 / 31 / 2000$ & $02 / 29 / 2000$ \\
$07 / 31 / 2013$ & $07 / 31 / 2013$ & $07 / 31 / 2013$ & $07 / 31 / 2013$ & $07 / 31 / 2013$
\end{tabular}


Exhibit 10

Results: Duration-Neutral Nominal Government Bond Momentum Strategy

UK

\begin{tabular}{|c|c|c|c|c|c|c|c|c|c|}
\hline & $-1-$ & $-2-$ & $-3-$ & $-4-$ & $-5-$ & $-6-$ & $-7-$ & $-8-$ & $-9-$ \\
\hline Lag Window (Months) & 5 & 6 & 7 & 8 & 9 & 10 & 11 & 12 & 13 \\
\hline Ave. Annual Return (bps) & 0.81049 & 7.851 & 0.25818 & 11.6636 & -30.4853 & 0.38043 & 17.921 & -13.8854 & 4.7715 \\
\hline Tracking Error & 144.0823 & 142.5455 & 139.3514 & 138.0238 & 133.7919 & 124.9649 & 122.2925 & 122.8159 & 124.9165 \\
\hline Information Ratio (IR) & 0.0056252 & 0.055077 & 0.0018527 & 0.084505 & -0.22786 & 0.0030443 & 0.14654 & -0.11306 & 0.038198 \\
\hline IR T-Statistic & 0.073343 & 0.71601 & 0.024014 & 1.092 & -2.9357 & 0.039105 & 1.8766 & -1.4434 & 0.48617 \\
\hline Skewness & 0.28033 & 0.1265 & 0.0061128 & -0.055978 & -0.25556 & 0.239 & 0.41309 & 0.18641 & 0.19817 \\
\hline Octile Skewness & 0.013257 & -0.065135 & -0.037827 & -0.033485 & -0.095164 & -0.046423 & 0.019651 & -0.10383 & -0.030409 \\
\hline$\%$ Excess Returns $>0$ & 48.8235 & 52.071 & 50.5952 & 50.8982 & 47.5904 & 50.303 & 52.439 & 50.9202 & 51.2346 \\
\hline Bid-Ask Significance Threshold (bps) & -5.4531 & -3.9516 & -7.7562 & -3.1767 & -16.7657 & -6.0453 & -0.32641 & -12.1634 & -5.5695 \\
\hline Ave. Rel. Weight: 1-3 yrs & 0.016764 & 0.013001 & 0.0088167 & 0.001869 & -0.0197 & -0.018817 & -0.026115 & -0.024284 & -0.028643 \\
\hline Ave. Rel. Weight: 3-5 yrs & -0.10341 & -0.095278 & -0.10228 & -0.11132 & -0.10841 & -0.10509 & -0.10815 & -0.11366 & -0.10638 \\
\hline Ave. Rel. Weight: 5-7 yrs & -0.045454 & -0.047683 & -0.041809 & -0.040341 & -0.027248 & -0.043733 & -0.026772 & -0.036034 & -0.044685 \\
\hline Ave. Rel. Weight: 7-10 yrs & -0.023989 & -0.03367 & -0.020818 & -0.013812 & 0.00022898 & 0.007693 & -0.00056439 & -0.012157 & -0.0067107 \\
\hline Ave. Rel. Weight: $10-20$ yrs & 0.28238 & 0.27658 & 0.26625 & 0.28401 & 0.29015 & 0.30259 & 0.31409 & 0.33351 & 0.34219 \\
\hline Ave. Rel. Weight: $20+$ yrs & -0.12629 & -0.11295 & -0.11016 & -0.12041 & -0.13502 & -0.14263 & -0.15249 & -0.14737 & -0.15577 \\
\hline Sample Start & 06/30/1999 & $07 / 31 / 1999$ & 08/31/1999 & 09/30/1999 & 10/31/1999 & $11 / 30 / 1999$ & $12 / 31 / 1999$ & $01 / 31 / 2000$ & $02 / 29 / 2000$ \\
\hline Sample End & $07 / 31 / 2013$ & $07 / 31 / 2013$ & $07 / 31 / 2013$ & $07 / 31 / 2013$ & $07 / 31 / 2013$ & $07 / 31 / 2013$ & $07 / 31 / 2013$ & $07 / 31 / 2013$ & $07 / 31 / 2013$ \\
\hline
\end{tabular}




\section{Exhibit 11}

United States: Coefficent Bounds

Dependent Variable: Long-Only Momentum Trading Rule Excess Returns: 2- through 5- to 13-month Lag Sample: 2/27/1998--6/28/2013

$-5-$

Independent Variable

Total Average Beta

Average Beta

Total Fraction

Barclays US Treasury Index Return

0.06935

0.06635

Signficant

Total Mean R Squared

Total Number of

Signal Size (Excess Return): 5-month Lag

Curve Factor (Third Principal Component)

S\&P 500 Return

1-month A2P2 Spread, Change

Barclays US Treasury Index Return $>0$

Level Factor (First Principal Component)

Non-farm Payroll Surprise (Standardized)

VIX, Change

3-month TED Spread, Change

MOVE Index, Change

MOVE Index, Lagged

1-month A2P2 Spread, Lagged

BBB Spread, Change

Slope Factor (Second Principal Component)

Barclays US Treasury Index Return, Lagged

Signal Size (Excess Return): 11-month Lag

3-month TED Spread, Lagged

Signal Size (Excess Return): 6-month Lag

Signal Size (Excess Return): 8-month Lag

10-year Treasury Liquidity Premium, Lagged

Gold Price Returns

Signal Size (Excess Return): 10-month Lag

Barclays US Treasury Index Return > 0, Lagged

Signal Size (Excess Return): 13-month Lag

Signal Size (Excess Return): 7-month Lag

Signal Size (Excess Return): 12-month Lag

BBB Spread, Lagged

10-year Treasury Liquidity Premium, Change

VIX, Lagged

Crude Oil Price Changes

$-0.40018$

0.33799

0.72222

0.06721

Regressions

0.00758

$-0.01499$

0.00917

0.53125

0.49306

0.00037

0.00091

0.00043

0.00029

$-0.00006$

0.00076

0.00002

$1.00 \mathrm{E}-05$

0.00049

$-0.00067$

0.0003

$-0.01645$

0.46875

0.00145

0.00037

0.00058

0.00049

$-0.00014$

0.00026

0.00002

0.00003

0.00055

$-0.00237$

0.01022

$-0.19837$

0.00061

$-0.11823$

$-0.10842$

$-0.00161$

0.00071

$-0.11784$

0.0004

0.00066

0.04259

0.00073

$-0.0876$

$-0.0014$

0.00174

$-0.18868$

0.13015

0.0008

$-0.18955$

0.07776

$-0.00046$

0.00418

0.00004

0.00116

$-0.1021$

$-0.00023$

0.00373

0

0.00121

Signal Size (Excess Return): 9-month Lag

0.08618

0.04132

0.04132

0.04611

0.03896

0.04132

0.04132

0.04099

0.04611

0.04099

0.04166

0.03654

0.04047

0.04132

0.02912

0.03026

0.03654

0.03706

0.0651

0.03654

0.04132

0.0392

0.03001

0.03582

0.01779

0.02658

0.04218

0.04611

0.04166

0.04132

0.03393
32

288

288

144

72

288

288

144
144

144

144

144

144

288

72

32

144

32

32

144 
Exhibit 12

United States: 3-Latent-Factor GATSMs (08/02/2013)

Instantaneous Forward Term Premiums

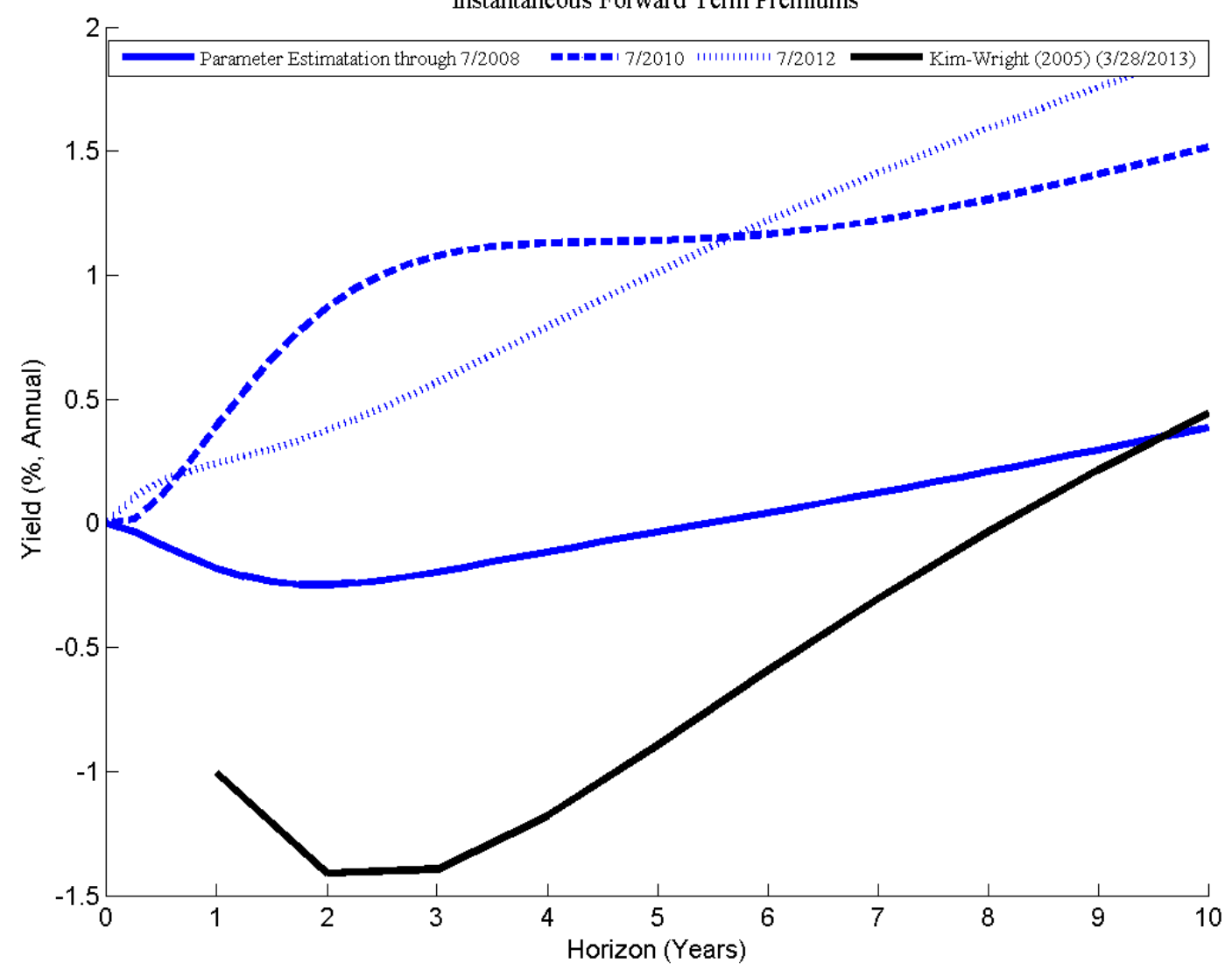

33 


\section{Exhibit 13}

Results: Duration-Neutral GATSM Portfolios

US

ATSM Sample End

Ave. Annual Return (bps)

Tracking Error

Information Ratio (IR)

IR T-Statistic

Skewness

Octile Skewness

$\%$ Excess Returns $>0$

Mean Turnover (per month)

Bid-Ask Significance Threshold (bps)

Ave. Rel. Weight: 1-3 yrs

Ave. Rel. Weight: 3-5 yrs

Ave. Rel. Weight: 5-7 yrs

Ave. Rel. Weight: 7-10 yrs

Ave. Rel. Weight: 10-20 yrs

Ave. Rel. Weight: 20+ yrs

Sample Start

Sample End
$-1-$

99.7658

147.8706

0.67468

9.5176

0.75346

0.15705

56.9892

0.13716

48.1298

$-0.26356$

$-0.088747$

0.38295

0.13056

$-0.066571$

$-0.094627$

$01 / 31 / 1997$

$07 / 31 / 2013$
$-2-$

2009
85.7582

85.7582

151.8876

7.9649

0.81286

0.18649

54.8387

0.13716

39.2805

$-0.34913$

0.028627

0.39364

0.13536

$-0.12701$

$-0.081494$

$01 / 31 / 1997$

$07 / 31 / 2013$
$-3-$

2010
13.5609

155.6925
0.0871

1.087

0.59686

$-0.013031$

48.3871

0.13716

$-4.9036$

$-0.34981$

0.013922

0.40387

0.1403

$-0.11679$

$-0.091489$

$01 / 31 / 1997$

07/31/2013

$\begin{array}{cc}-4- & -5- \\ 2011 & 2012\end{array}$

$36.3277-46.009$

$153.9664 \quad 154.6292$

$0.23595 \quad 0.29754$

$3.3284 \quad 4.1974$

$0.13832 \quad 0.40631$

$0.065599 \quad 0.012588$

$\begin{array}{ll}51.0753 & 51.6129\end{array}$

$0.13716 \quad 0.13716$

$\begin{array}{ll}0.0739 & 14.8999\end{array}$

$-0.34847 \quad-0.28651$

$-0.13461 \quad-0.15598$

$0.54129 \quad 0.45321$

$0.18422 \quad 0.19896$

$-0.12683 \quad-0.09408$

$-0.1156 \quad-0.1156$

$01 / 31 / 1997 \quad 01 / 31 / 1997$

$07 / 31 / 2013 \quad 07 / 31 / 2013$ 
Exhibit 14

Distribution of Momentum Returns Term Premium Betas

Average Beta: (0.60538), Average T Statistic (10.7299)

Total Number of Regressions: (45), Average R-squared: (0.3726)

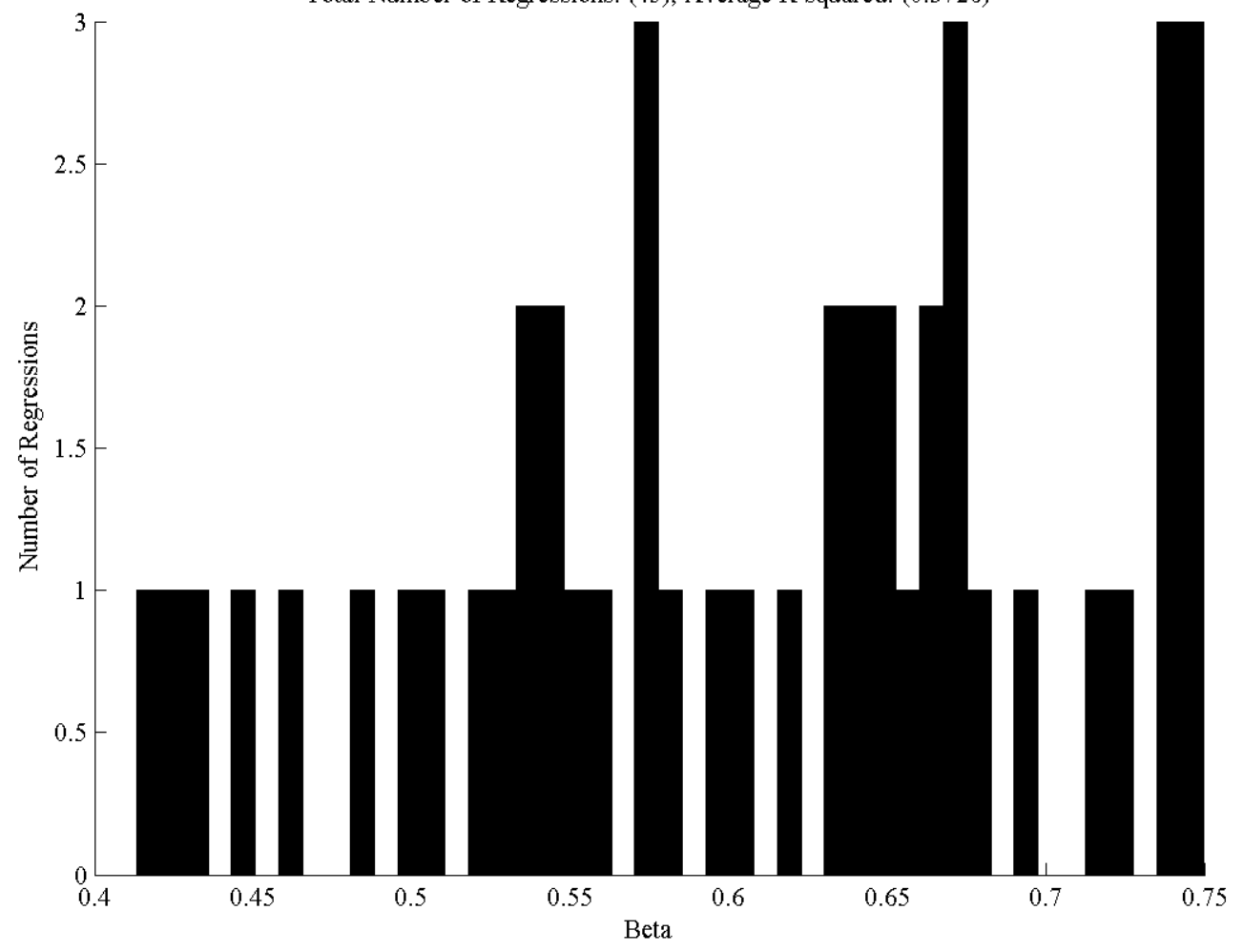

Exhibit 15

Distribution of Momentum Returns Term Premium Alphas Average Alpha: (5.2487) (basis points), Average T Statistic (2.1426) Total Number of Regressions: (45), Average R-squared: (0.3726)

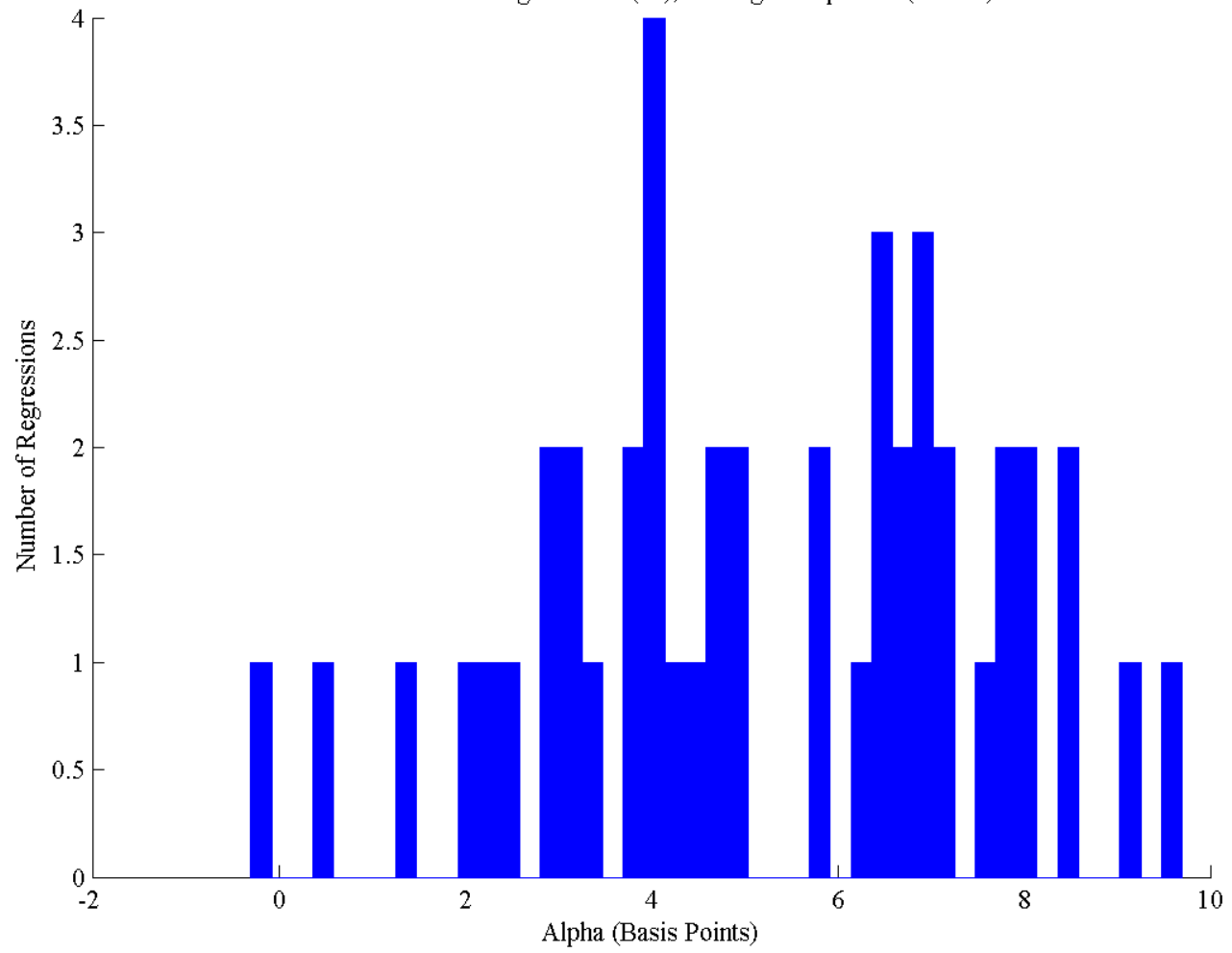


Exhibit 16

Distribution of Momentum Alphas: Yield Curve Principal Component Regressions Average Alpha: (15.6352) (basis points), Average T Statistic (2.1328)

Average T Statistics: Level (1.1699), Slope: (0.082137), Curvature (1.9656)

Total Number of Regressions: (9), Average R-squared: (0.010363)

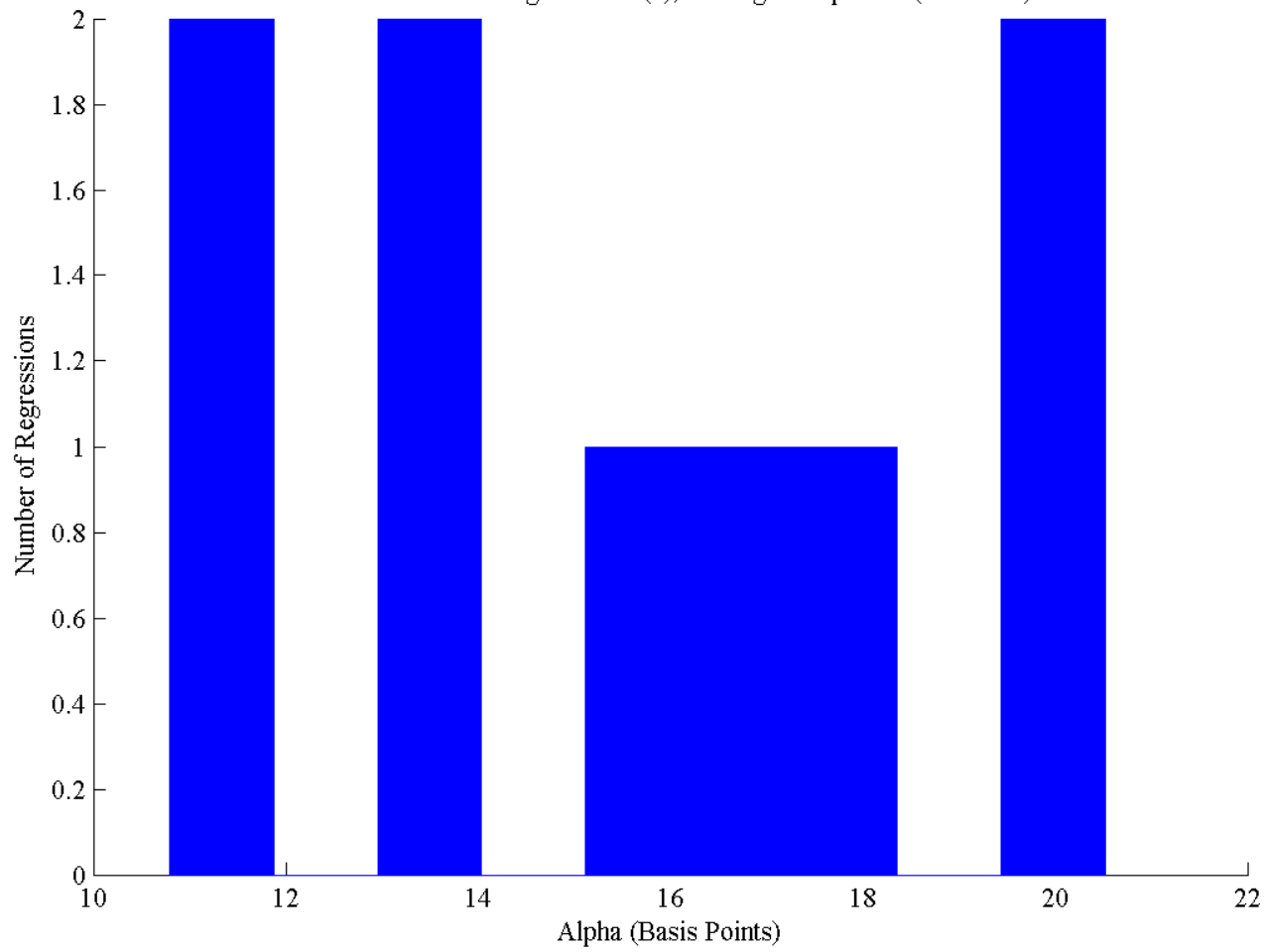

Exhibit 17

Distribution of Momentum Alphas (Long-Short): Yield Curve Principal Component Regressions Average Alpha: (21.6741) (basis points), Average T Statistic (1.9822)

Average T Statistics: Level (0.95065), Slope: (-1.0122), Curvature (0.65599)

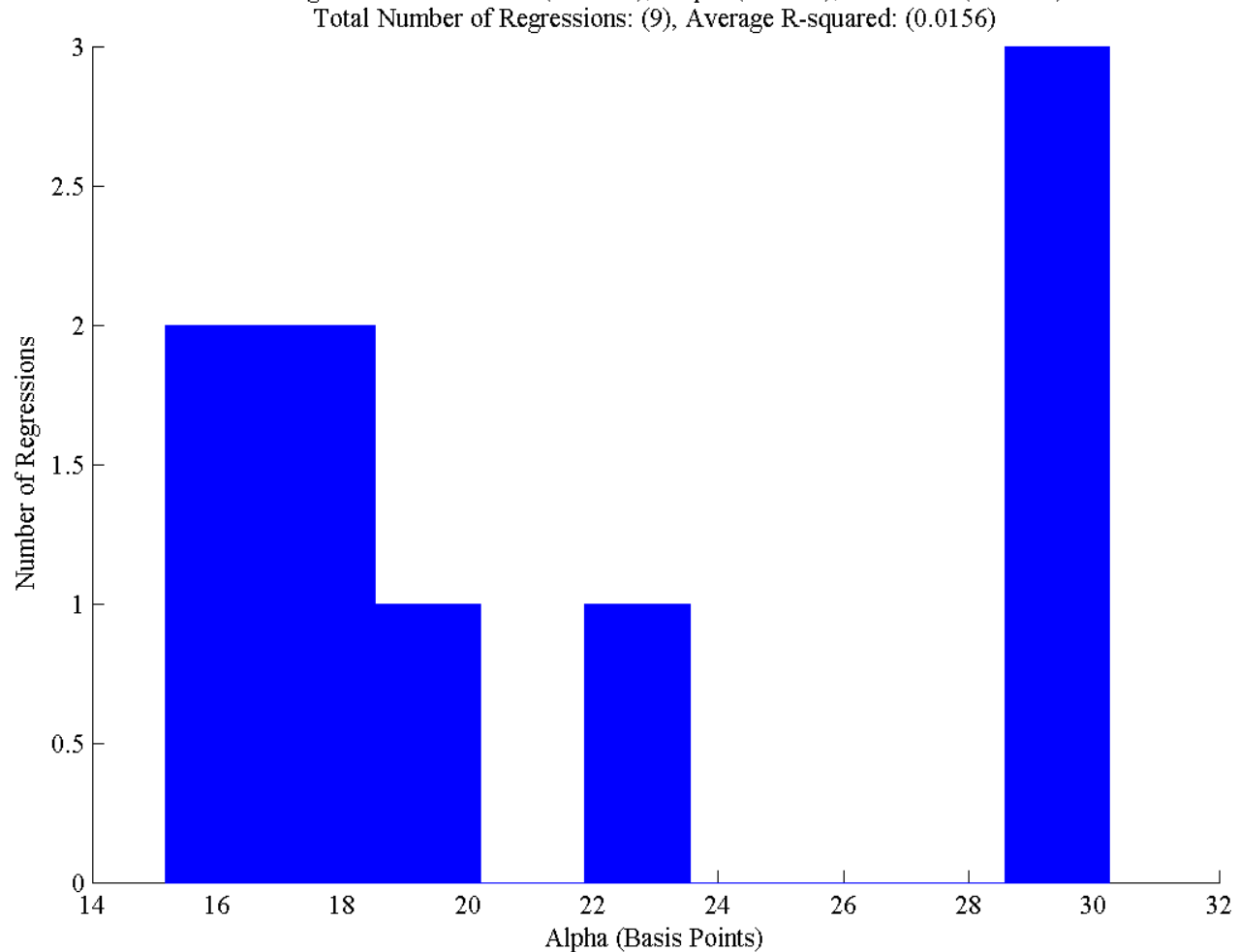




\section{References}

Adrian, Tobias, Richard Crump and Emanuel Moench, 2013, "Pricing the Term Structure with Linear Regressions," Journal of Financial Economics, vol. 110, pp. 110-138.

Adrian, Tobias, Richard Crump and Emanuel Moench, 2013, "Efficient Regression-Based Estimation of Dynamic Asset Pricing Models," Federal Reserve Bank of New York Staff Reports, No. 493.

Asness, Clifford S., Tobias J. Moskowitz, and Lasse Pedersen, 2013, "Value and Momentum Everywhere," Journal of Finance, vol. 62, pp. 929-985.

Asness, Clifford S., John M. Liew, and Ross L. Stevens, 1997, "Parallels Between the CrossSectional Predictability of Stock and Country Returns," Journal of Portfolio Management, vol. 23, pp. 79-87.

Balduzzi, Pierluigi, Edwin J. Elton, and T. Clifton Green, 2001, "Economic News and Bond Prices: Evidence from the U.S. Treasury Market," Journal of Financial and Quantitative Analysis, vol. 36, pp. 523-43.

Barberis, Nicholas, Andrei Shleifer, and Robert Vishny, 1998, "A Model of Investor Sentiment," Journal of Financial Economics, vol. 49, pp. 307-43.

Bauer, Michael D., Glenn D. Rudebusch, and Cynthia Jing Wu, 2011. "Unbiased Estimate of Dynamic Term Structure Models," Working Paper Series 2011-12, Federal Reserve Bank of San Francisco.

Cutler, David M., James M. Poterba, and Lawrence H. Summers, 1990, "Speculative Dynamics and the Role of Feedback Traders," NBER Working Paper Series, No. 3243.

Cutler, David M., James M. Poterba, and Lawrence H. Summers, 1991, "Speculative Dynamics," Review of Economic Studies, vol. 59, pp. 529-46.

Daniel, Kent, David Hirshleifer, and Avanidhar Subrahmanyam, 1998, “Investor Psychology and Security Market Under- and Overreactions” Journal of Finance, vol. 53, pp. 1839-85.

DeBondt, Werner F.M. and Richard Thaler, 1985, "Does the Stock Market Overreact, Journal of Finance, vol. 40, pp. 793-805.

Durham, J. Benson, 2001, "Sensitivity Analyses of Anomalies in Developed Stock Markets," 2001, Journal of Banking and Finance, vol. 25, pp. 1503-1541.

Durham, J. Benson, 2013, “Are U.S. Treasury Term Premiums Really So Low?,” working paper.

Fama, Eugene F. and Kenneth R. French, 1992, "The Cross-Section of Expected Stock Returns," Journal of Finance, vol. 47, no. 2, pp. 427-65. 
Fama, Eugene F., 1998, "Market Efficiency, Long Term Returns, and Behavioral Finance," Journal of Finance, vol. 49, pp. 283-306.

Ferson, W., 1996, "Warning: Attribute-sorted portfolios can be hazardous to your research," Saitou, S., Sawaki, K., Kubota, K. (Eds.), Modern Portfolio Theory and its Applications, Center for Academic Societies, Osaka Japan, pp. 21-32.

Flemming, Michael J., 2003, "Measuring Treasury Market Liquidity," Federal Reserve Bank of New York Economic Policy Review, pp. 83-108.

Fornari, Fabio, 2004, "Macroeconomic Announcements and Implied Volatilities in Swaption Markets, BIS Quarterly Review, pp. 79-86.

Frazzini, Andrea, 2006, “The Disposition Effect and Underreaction to News," Journal of Finance, vol. 61, pp. 2017-46.

Frydman, Cary, Nicholas Barberis, Colin Camerer, Peter Bossaerts, and Antonio Rangel, 2013, "Testing Theories of Investor Behavior Using Neural Data," mimeo.

Gorton, Gary B., Fumio Hayashi, and K. Geert Rouwenhorst, 2012, "The Fundamentals of Commodity Futures Returns," Yale ICF Working Paper No. 07-08.

Granger, Clive, and Harold Uhlig, 1990, "Reasonable Extreme-Bound Analysis," Journal of Econometrics, vol. 44, pp. 159-170.

Hamilton, James D., and Jing Cynthia Wu, 2012, “Testable Implications of Affine Term Structure Models," forthcoming, Journal of Econometrics.

Ilmanen, Antti, 2011, Expected Returns: An Investor's Guide to Harvesting Market Rewards, John Wiley and Sons.

Jegadeesh, Narasimhan and Sheridan Titman, 1993, "Returns to Buying Winners and Selling Losers: Implications for Stock Market Efficiency," Journal of Finance, vol. 48, pp. 699-720.

Jegadeesh, Narasimhan and Sheridan Titman, 2001, "Profitability of Momentum Strategies: An Evaluation of Alternative Explanations," Journal of Finance, vol. 56, pp. 65-91.

Jostova, Gergana, Stanislava Nikolova, Alexander Philipov, and Christof W. Stahel, 2013, "Momentum in Corporate Bond Returns," The Review of Financial Studies, vol. 26, pp. 16491693.

Kim, Don H. and Jonathan H. Wright, 2005, “An Arbitrage-Free Three-Factor Term Structure Model and the Recent Behavior of Long-Term Yields and Distant-Horizon Forward Rates," Finance and Economics Discussion Series (The Federal Reserve Board), 2005. 
Langetieg, T., “A Multivariate Model of the Term Structure,” 1980, Journal of Finance, vol. 35, pp. 71-97.

Laopodis, Nikiforos T., 2010, "Dynamic Linkages among Major Sovereign Bond Yields," Journal of Portfolio Management, vol. 36, pp. 74-87.

Leamer, Edward, 1983, "Let's Take the Con out of Econometrics," American Economic Review, vol. 73, pp. 31-43.

Menkhoff, LU.K.as, Lucio Sarno, Mailk Schmeling, and Andreas Schrimpf, 2012, "Currency Momentum Strategies," Journal of Financial Economics, vol. 106, pp. 660-684.

Moskowitz, Tobias J. Yao Hua Ooi, and Lasse Heje Pedersen, 2011, “Time Series Momentum," Journal of Financial Economics, vol. 104, pp. 228-50.

Novy-Marx, Robert, 2012, "Is Momentum Really Momentum?” Journal of Financial Economics, vol. 103, pp. 429-453.

Rouwenhorst, K. Geert, 1998, "International Momentum Strategies," Journal of Finance, vol. 53, pp. 267-284.

Scheifer, Andrei and Robert W. Vishny, 1997, "The Limits of Arbitrage," Journal of Finance, vol. 52, pp. 35-55.

Vasicek, O., 1977, "An Equilibrium Characterization of the Term Structure of Interest Rates," Journal of Financial Economics, vol. 5, pp. 177-188. 